\title{
Segmentación del empleo y apreciación de la educación en un modelo productivo anclado. Análisis comparativo entre España y Argentina
}

\author{
Pedro López-Roldán \\ Centre d'Estudis Sociològics sobre la Vida Quotidiana i el Treball \\ Institut d'Estudis del Treball \\ Universitat Autònoma de Barcelona. Departament de Sociologia \\ pedro.lopez.roldan@uab.es \\ ORCID: 0000-0001-8775-2181
}

\section{Sandra Fachelli}

Universitat de Barcelona. Departament de Sociologia

Universitat Autònoma de Barcelona. Grup de Recerca en Eduació i Treball /

Departament de Sociologia

sandra.fachelli@uab.es

ORCID: 0000-0002-7155-636X

Recepción: 17-04-2018

Aceptación: 10-07-2018

Publicación: 15-01-2019

\section{Resumen}

El artículo plantea dos cuestiones principales desde un ejercicio analítico comparativo entre España y Argentina. Por un lado, nos preguntamos hasta qué punto los procesos de segmentación del mercado de trabajo generan dinámicas de estructuración de las desigualdades laborales semejantes en ambos países y qué aspectos son específicos de una realidad laboral que se sitúa en diferentes contextos culturales, sociales, económicos e históricos. En este sentido, se corrobora la hipótesis general que establece que no existe un único mercado de trabajo que ajusta oferta y demanda, que, por el contrario, se diferencian diversos segmentos que estructuran posiciones jerárquicas en el mercado laboral en correspondencia con ciertos perfiles específicos de la oferta de trabajo, y se constata la alta correspondencia en la configuración de los segmentos de empleo entre España y Argentina. Por otro lado, dada la estructura de segmentación del empleo, nos planteamos en qué medida se da en ambos países la mal nominada sobreeducación de la ocupación de la fuerza de trabajo y la supuesta devaluación de las credenciales educativas. Entendiendo que el fenómeno debe mirarse desde el lado de la demanda y dadas las estructuras productivas ancladas e internamente diferenciadas de ambos países, el fenómeno, que preferimos identificar como «subocupación", es de mayor importancia en España que en Argentina dada la expansión educativa experimentada y la consecuente mayor dificultad de absorber la fuerza de trabajo cualificada en los sectores más productivos por la incapacidad del modelo productivo de generar puestos de trabajo acordes.

Palabras clave: segmentación del mercado de trabajo; modelo productivo; devaluación de credenciales; subocupación; desigualdad social; análisis comparativo; España; Argentina 
Abstract. Employment segmentation and appreciation of education in an anchored production model: Comparative analysis between Spain and Argentina

This article addresses two main issues through a comparative analytical exercise of Spain and Argentina. Firstly, we examine to what extent labour market segmentation processes produce similar dynamics of structuring labour inequalities in both countries and what aspects are specific to a labour reality situated in different cultural, social, economic and historical contexts. In this regard, the general hypothesis establishes that there is no single labour market that adjusts supply and demand but rather diverse segments that structure hierarchical positions in the labour market according to specific labour supply profiles, and that the configuration of the employment segments in Spain and Argentina show a high correspondence. Secondly, given the structure of employment segmentation, we consider to what extent the misnamed 'occupational overeducation' of the labour force and the supposed devaluation of educational credentials occur in both countries. Understanding that the phenomenon should be viewed from the demand side and given the anchored and internally differentiated production systems of both countries, this phenomenon, which we prefer to call 'underoccupation', is of greater importance in Spain than in Argentina given the country's educational expansion and hence the greater difficulty to absorb the qualified workforce in the most productive sectors due to the inability of the productive model to create commensurate jobs.

Keywords: labour market segmentation; productive model; devaluation of credentials; underoccupation; social inequality; comparative analysis; Spain; Argentina

\begin{aligned} & \multicolumn{2}{c}{ Sumario } \\ & 1. Introducción 4. Conclusiones \\ & 2. Perspectiva teórica, modelo de análisis Referencias bibliográficas \\ & y metodología Anexo \end{aligned}

3. Resultados

\section{Introducción}

En el contexto del proyecto de la red INCASI (International network for comparative analysis of social inequalities) ${ }^{1}$, destinado a la investigación comparativa de las desigualdades sociales entre Europa y América Latina, estamos elaborando un marco analítico general sobre esta problemática donde interrelacionamos distintas dimensiones y ámbitos sociales en los que se expresan las desigualdades y donde se enfatiza el carácter dinámico del fenómeno en términos de

1. Este artículo se ha elaborado en el contexto de la Red INCASI, un proyecto europeo que ha recibido fondos del programa de investigación e innovación Horizonte 2020 de la Unión Europea en el marco del programa Marie Skłodowska-Curie, GA No 691004, y coordinado por el Dr. Pedro López-Roldán. Este artículo refleja solo la opinión del autor y la Agencia no es responsable del uso que pueda hacerse de la información que contiene. El artículo es una continuación y actualización de un trabajo anterior de los autores (López-Roldán y Fachelli, 2017a). 
trayectorias y cursos de vida (López-Roldán y Fachelli, 2017b). En particular, nuestra perspectiva se inscribe en un modelo general donde se pone especial atención a la interrelación existente entre los ámbitos educativo, productivo y reproductivo, mirada que permite, desde los recursos y estrategias de los grupos y sujetos sociales, observar la articulación de los procesos sociales en aquellas tres esferas centrales de la vida de las personas, desde donde se construyen y explican la generación y cristalización de las desigualdades sociales en términos de estratificación social. No obstante, en este trabajo no abordaremos las interrelaciones con el ámbito reproductivo.

En este marco general, el artículo se plantea dos cuestiones principales desde un ejercicio analítico comparativo entre países, en particular entre España y Argentina. Por un lado, nos preguntamos hasta qué punto los procesos de segmentación del mercado de trabajo generan dinámicas de estructuración de las desigualdades laborales semejantes en ambos países y qué aspectos son específicos de una realidad laboral que se sitúa en diferentes contextos culturales, sociales, económicos e históricos. Por otro, dada una estructura de segmentación del empleo, nos planteamos en qué medida se da en ambos países la mal nominada sobreeducación de la ocupación de la fuerza de trabajo y una supuesta devaluación de las credenciales educativas.

El análisis de la segmentación del mercado de trabajo es una perspectiva que nos permite estudiar la cristalización de las dinámicas socioeconómicas de nuestro entorno en forma de desigualdad de condiciones del empleo y posiciones laborales jerarquizadas. El proceso de segmentación es la respuesta a un conjunto de factores que se vienen dando desde hace décadas en un contexto de múltiples transformaciones, entre ellas: las estrategias laborales y organizativas de las empresas; una nueva estructura económica con la expansión de los servicios, con cambios tecnológicos incesantes; el debilitamiento de los sindicatos; las nuevas regulaciones del mercado laboral; las fluctuaciones macroeconómicas; la internacionalización de los sistemas de producción; la incorporación de la mujer al ámbito productivo, y los cambios demográficos. Estos son factores que favorecen la proliferación de nuevas formas de relaciones laborales con una distribución desigual de la calidad que dan lugar a formas de empleo no estándar, formas contractuales que en buena parte de los casos llevan asociadas la precarización de las condiciones laborales y la dificultad de alcanzar niveles aceptables de lo que la Organización Internacional del Trabajo conceptualiza como trabajo decente (ILO, 1999)².

Internacionalmente, crece de forma general el trabajo temporal, a tiempo parcial, la subcontratación o el trabajo por cuenta propia dependiente, y se mantienen altos niveles de informalidad, y así se rompe la norma del empleo estable. En el conjunto de los países de la OCDE se estima que en el periodo 1995 a 2013 el 56\% del crecimiento del empleo se atribuye a las distintas

2. El trabajo decente y sus cuatro pilares, creación de empleo, protección social, derechos en el trabajo y diálogo social, son elementos centrales de la nueva Agenda 2030 de Desarrollo Sostenible de Naciones Unidas. 
formas de empleo no estándar (OCDE, 2015: 146). Su importancia creciente está generando cambios estructurales en el ámbito laboral, pues son formas de relación laboral que alimentan la dualización del mercado de trabajo y configuran, en particular, un segmento secundario inmerso en situaciones crecientes de incertidumbre, inseguridad y falta de protección social, devaluando las condiciones de vida de un importante sector de la sociedad. Para una parte de estas personas, estar en el segmento secundario, puede suponer una etapa inicial de inserción en el mercado laboral, o una etapa coyuntural en su trayectoria, o incluso obedecer a una decisión buscada, pero para muchos de estos trabajadores y trabajadoras es la única posibilidad de trabajo, es una situación no voluntaria y encuentra barreras difícilmente franqueables para salir de ese segmento, con consecuencias de privación en sus condiciones laborales y de vida. Ante ellas se requiere diseñar políticas públicas que las contrarresten, si se entiende que es un objetivo de justicia social reducir las desigualdades sociales que comporta para los sectores más débiles de la sociedad, y entendiendo también que las estrategias de flexibilización de la mano de obra pueden representar reducciones de costes a corto plazo, pero comportan a largo plazo pérdidas de productividad y opciones de innovación (ILO, 2016).

Los procesos de segmentación del mercado de trabajo, mirados desde el indicador de las formas de contratación atípicas, se han extendido de forma generalizada en la Unión Europea en las últimas décadas. En la reciente crisis económica, han tenido efectos distintos dependiendo del país, si bien el patrón general más común es el declive de la calidad del empleo (Piasna, 2017). España es bien conocida como un caso extremo en la Unión Europea junto a Polonia, que llegó a alcanzar niveles del 35\% de contratos temporales en las décadas pasadas, además de mantener altas tasas de desempleo que oscilan según los vientos de los ciclos económicos. La crisis de 2008 mostró justamente las debilidades de este empleo expulsando a un gran número de asalariados/ as temporales hacia el desempleo, ilustrando el «efecto luna de miel» de las reformas marginales (Boeri y Garibaldi, 2007), y reduciendo de esa manera la tasa de temporalidad a niveles del $25 \%$. Pero esta modalidad de contratación siguió siendo la forma predominante de la nueva contratación. El marco de regulación del empleo temporal frente al empleo indefinido por el diferente tratamiento de los costes de despido y su utilización como estrategia empresarial de ajuste explica el mantenimiento de esta situación (Banyuls y Recio, 2017), así como la debilidad de las políticas de empleo implementadas para contrarrestar esas tendencias o, por el contrario, para fomentarlas en una tendencia general de desregulación e individualización de la relaciones laborales (Alós, Beneyto y Jódar, 2017). De hecho, en consonancia con la misma tendencia en Europa, las reformas políticas han buscado la flexibilización del mercado de trabajo y han encontrado en la contratación temporal atípica una clara vía de acción más allá de los sectores de baja productividad y ocupaciones de baja calidad (Molina y López-Roldán, 2015).

Desde una perspectiva más amplia, esos rasgos son los propios del modelo de empleo español que se identifica como neoliberal mediterráneo (Banyuls et 
al., 2009). Este modelo es el resultado de la confluencia de diversas características definitorias: una estructura productiva de servicios con un predominio de la pequeña y mediana empresa, donde destaca el uso intensivo de la mano de obra, las bajas cualificaciones y la relativa baja productividad; un sistema productivo separado del educativo; prácticas empresariales tayloristas, con estrategias de reducción de costes y flexibilización externa de la gestión laboral escasamente interesada en la formación; una economía que incluye el trabajo sumergido; escaso número de empresas grandes con alto nivel tecnológico; la limitación de la acción sindical al ámbito primordial de la gran empresa que no se puede ejercer en el amplio tejido de empresas pequeñas, si bien los sindicatos cuentan con un importante reconocimiento y legitimación institucional. Todo ello ha conducido a alcanzar y mantener una alta segmentación del mercado de trabajo y altos niveles de desempleo. A ello se suma un sistema de bienestar débil, donde, si bien también hay que reconocer que el Estado ha mejorado sus prestaciones de servicios y transferencias desde la instauración de la democracia, el sistema fiscal y las políticas que restringen el sector público no acaban de resolver, con relación a Europa, las desigualdades que ese modelo de empleo genera y tiene que ser suplido por la solidaridad proveedora de las propias familias, con los efectos que ello supone para romper con las desigualdades de género si se defiende un modelo social equitativo de tiempos y actividades de la vida cotidiana. El balance de los últimos cuarenta años es el de profundos y rápidos cambios que han llevado a la modernización del país ${ }^{3}$, pero que se conjugan con la persistencia de problemas históricos estructurales que reproducen las desigualdades sociales, agravadas tras la crisis, en un modelo social de bajo coste (Martín-Artiles, 2008).

El caso de Argentina manifiesta algunos elementos comunes con el modelo español, si bien con una realidad socioeconómica distinta y agravada en tanto que país periférico, en particular, por sus menores capacidades tecnológicas, pero donde se dan también diferencias importantes internas en su estructura productiva entre sectores con alta y baja productividad, en contextos de inestabilidad macroeconómica y altos niveles de inflación. El mercado laboral argentino muestra sus especificidades en un marco de alto nivel de regulación. Con relación a la contratación temporal, Argentina es distinta, pues es una modalidad de relación laboral relativamente escasa, del orden del 10\%, con una tendencia a reducirse como resultado de los cambios de regulación a partir de 2002 destinados a desincentivar su uso. La Ley de Contratos Laborales establece como norma general que las relaciones laborales son permanentes, si bien existen contratos de duración determinada que no excedan los cinco años, estacionales o temporales para necesidades específicas de las empresas, todos ellos con garantías similares a las de los permanentes (Maurizio, 2016). Pero, por otro lado, existe un gran volumen de trabajo informal de carácter asalariado o cuentapropista que congrega en buena parte los mismos efectos de debilidad

3. En el sentido de avance tecnológico, terciarización de la economía y acercamiento a los niveles de desarrollo de los países más avanzados. 
en el empleo y de las condiciones de trabajo, por lo que, en Argentina, y también de forma general en América Latina, cabe hablar de un doble proceso de segmentación: el derivado de la división entre trabajo permanente y temporal y el derivado de la división entre trabajo formal e informal (ILO, 2016: 62).

Uno de los rasgos generales más destacables de ambos países es la identificación como países de industrialización tardía. Ishida y Miwa (2011) los definen como aquellos que han tenido un desarrollo industrial tardío pero rápido, y que hacia 1975 habían experimentado una reducción significativa en el sector rural y de la producción agrícola a favor de un sector industrial y, más notablemente, el crecimiento del sector de servicios. Por otro lado, es relevante para ambos países el carácter determinante de su estructura productiva, anclada en la reproducción de una diferenciación de sectores de baja y alta productividad a los que se asocian, altas y bajas cualificaciones, así como buenas y malas condiciones de trabajo.

En estas páginas presentamos los avances parciales realizados en el estudio de los procesos de desigualdad con relación al mercado de trabajo y su vínculo con los niveles educativos de los trabajadores y trabajadoras, en un ejercicio de investigación comparativa entre España y Argentina. El artículo se divide en tres apartados: explicitamos la perspectiva teórica, el modelo de análisis y la metodología empleada; presentamos los principales resultados del análisis y elaboramos unas conclusiones finales.

\section{Perspectiva teórica, modelo de análisis y metodología}

\subsection{Perspectiva teórica}

Los resultados de la investigación que presentamos en estas páginas tienen en cuenta dos aproximaciones teóricas principales: la de la segmentación del mercado de trabajo y la de la relación entre educación y mercado de trabajo que repasamos seguidamente. ${ }^{4}$

\subsubsection{La perspectiva de la segmentación del mercado de trabajo}

Desde el punto de vista de la segmentación, la división entre empleos atípicos y empleos estándar es una dimensión fundamental para determinar la estratificación que implican los segmentos del mercado de trabajo, pero es insuficiente para dar cuenta de la complejidad de un fenómeno que va más allá de una visión de insiders y outsiders y de la brecha salarial que conlleva (Dickens y Lang, 1988). Además, cabe relacionarlo, en un determinado marco

4. Nuestro análisis del mercado de trabajo y de las credenciales educativas se sitúa en un marco más general teórico-analítico que estamos desarrollando en el contexto del proyecto INCASI (López-Roldán y Fachelli, 2017b), en términos de lo que denominamos modelo AMOSIT (Analytical Model on Social Inequalities and Trajectories), donde, desde un planteamiento dinámico que tiene en cuenta las trayectorias vitales y la movilidad social, analizamos el mercado de trabajo en relación con las desigualdades sociales, en particular, relacionando el mercado de trabajo con el sistema educativo y el trabajo reproductivo y la vida cotidiana. 
de regulación más o menos proclive, con las prácticas de gestión laboral de los empleadores/as (Banyuls et al., 2009), en particular, con la política de externalización de las empresas (Recio, 1991). Asimismo, el sector de actividad, el tamaño de la empresa o la capacidad de negociación de los trabajadores y trabajadoras son variables explicativas importantes, así como las características propias de la estructura productiva en la que se dan las dinámicas del mercado laboral (Fina y Toharia, 1987; Banyuls et al., 2017).

La perspectiva teórica heterodoxa de la segmentación del mercado de trabajo apunta en esta dirección y recoge una tradición de varias décadas de análisis y explicación de los procesos de estructuración de los mercados de trabajo de las economías capitalistas. Cuestionando el modelo neoclásico de mercado único ajustado en precios y cantidades según la lógica de la libre competencia y la teoría del capital humano, la perspectiva segmentacionista destaca el fragmentado funcionamiento de mercado de trabajo capitalista. Pone el acento en la diversificación del mercado laboral regido por normas específicas resultado de dinámicas sociales y de poder de los actores en función de los mecanismos explicativos que cada escuela ha razonado con sus especificidades. En este sentido, la teoría de la segmentación del mercado de trabajo reúne un conjunto de aproximaciones teóricas y análisis empíricos preocupados por explicar las desigualdades sociales que se producen por las posiciones ocupadas en el ámbito del trabajo asalariado como resultado de la confluencia de procesos sociales de articulación de factores relacionados tanto con la demanda como con la oferta de trabajo.

Recogiendo las aportaciones de Leontaridi (1998), Rubery (2007), Sánchez-López (2008) y Fernández-Huerga (2010), se pueden identificar cuatro orientaciones en la perspectiva teórica heterodoxa de la segmentación del mercado de trabajo. El trabajo seminal de la Escuela (Neo)Institutionalista (Doeringer y Piore, 1985), donde, desde la centralidad del lado de la demanda, la perspectiva del dualismo industrial, del cambio tecnológico, la organización de la producción y las instituciones, adoptando una perspectiva dualista, diferencian entre un mercado primario (de puestos de trabajo de calidad, estables, bien remunerados, cualificados y con posibilidades de promoción) y un mercado secundario (de puestos de baja calidad, inestables, con bajos salarios, alta rotación y poco cualificados). Introdujeron la distinción entre mercado interno y externo de trabajo con normas de regulación diferenciadas (Osterman, 1985).

La orientación marxista de la Escuela Radical estadounidense (Gordon, Edwards y Reich, 1986) enfatizó la perspectiva histórica del sistema de acumulación capitalista y la centralidad del dualismo industrial, dando cuenta de las estrategias empresariales de división del trabajo y de control del conflicto laboral y proponiendo la existencia de una tríada de segmentos, diferenciando en el segmento primario el independiente del dependiente, además del secundario. Destacó, en particular, las correspondencias entre los segmentos generados en el contexto de las relaciones sociales de producción y las características de la oferta como el sexo, la raza o la educación. 
El enfoque del estructuralismo sociológico (Beck, Horan y Tolbert, 1978; Kalleberg, Wallace y Althauser, 1981) destacó la importancia de los factores estructurales de los puestos de trabajo vinculados a las características de la empresa (tamaño, sector de actividad, productividad), pues en función de ellas se podían ofrecer mejores condiciones laborales a sus trabajadores/as (de ingresos, promoción, etcétera). Cuestionaron, en particular, la estrategia empírica recurrente de expresar el dualismo en términos de sectores productivos de la economía (centrales y periféricos), planteando la heterogeneidad que se produce en el interior tanto de un sector como de una empresa.

Finalmente, la tradición europea desarrollada en torno a la llamada Escuela de Cambridge (entre otros, Rubery, 1978; Wilkinson, 1981; Craig et al., 1982; Humphries y Rubery, 1984; Sengenberger, 1988; Rubery y Wilkinson, 1994; Villa, 1990; Marsden, 1999; Michon, 2007), que señalan, junto a la relevancia de los aspectos institucionales y de los elementos contextuales de la organización, la existencia de una multicausalidad de factores que configuran los segmentos del mercado de trabajo interno y externo, su diversificación, así como la relevancia de las características de la oferta de trabajo y los aspectos relativos a la reproducción social. De la confluencia se deriva la literatura que analiza los llamados modelos nacionales de empleo (Bosch et al., 2009), y de la integración de tres tradiciones teóricas, la de la segmentación del mercado de trabajo, la socioeconomía feminista y la institucionalista comparativa, surge una propuesta teórica renovada de la perspectiva segmentacionista (Grimshaw et al., 2017).

Teniendo en cuenta los planteamientos heterodoxos de la literatura segmentacionista, durante los años 90, en el seno del grupo de investigación QUIT (Centro de Estudios Sociológicos sobre la Vida Cotidiana y el Trabajo), se desarrolló un modelo analítico de operacionalización y medición de la segmentación en términos de empleo donde se tienen en cuenta cuatro dimensiones generales fundamentales: la seguridad en el empleo, la cualificación, las características de las empresas y los ingresos (López-Roldán, 1996). Este modelo sirvió para dar cuenta de una investigación sobre las relaciones entre trabajo productivo y vida cotidiana (López-Roldán et al., 1998; Miguélez y Torns, 1998) y ha orientado otros trabajos de investigación del equipo donde se han planteado análisis de segmentación laboral (Miguélez y López-Roldán, 2014; Miguélez et al., 2011), y que seguiremos en este artículo. Este modelo de referencia se aplicará en esta investigación, tanto para el caso de España como el de Argentina.

En la literatura española y argentina se ha adoptado en distintas contribuciones la perspectiva de la segmentación laboral como referente explicativo de estructuración de los mercados de trabajo. Entre las españolas, podemos citar los trabajos de Recio (1988), Huguet (1999), Polavieja (2003), Alós-Moner (2008), Sánchez-López (2008), García-Nogueroles (2009), Fernández-Huerga (2012) y García-Serrano y Malo (2013). Entre las contribuciones argentinas, destacamos las de Salvia y Vera (2003, 2016), Neffa (2008), Alzúa (2009), 
Vera (2013), Paz (2013), Bertranou et al. (2014), Beccaria y Groisman (2015) y Poy (2017).

En el caso argentino, la visión estructuralista de algunos de esos trabajos (Salvia, 2012; Chávez-Molina y Pla, 2013) se ha visto acompañada y se ha inscrito en una formulación teórica más general explicativa de la realidad económico-productiva de América Latina. Desde la denominada teoría de la heterogeneidad estructural propuesta en los años setenta por Pinto (1970), heredera de la propuesta de Prebisch (1949), se adopta una perspectiva de estructuralismo histórico para entender el funcionamiento económico y social de los países latinoamericanos 5 . Se entiende que se da una coexistencia de sectores de la economía modernos de alta productividad, similares a la de los países más desarrollados, con otros de baja productividad en actividades informales. La segmentación laboral sería la consecuencia de esas constricciones productivas, que tendrían su corolario en una segmentación de empleos en el mercado de trabajo entre actividades laborales de subsistencia propios del segmento secundario y empleos formales en sectores formales privados y públicos propios del segmento primario, y, más allá, de desigualdades en las condiciones de vida, que son persistentes en el tiempo.

Coincidiendo con los planteamientos generales de esta perspectiva, en nuestra aproximación no introduciremos la restricción de definir a priori una clasificación de los sectores informales y formales, si bien incluiremos una categoría que identifique el empleo informal, para entender que se pueden dar, sobre todo en el sector formal, procesos de segmentación del empleo internos con rasgos diferenciados de segmento primario y secundario que interaccionan con la categorización sectorial. No obstante, cabe esperar una alta correspondencia entre una y otra aproximación.

\subsubsection{La relación entre educación y mercado de trabajo}

El análisis de la relación entre formación y empleo ha dado lugar a una extensa literatura de teorización y análisis. Aquí nos interesa destacar esta relación desde el punto de vista de la conceptualización de la idea de sobreeducación (overeducation). Kucel (2011) realiza un interesante análisis de las teorías que pueden ser vinculadas con ese concepto, y distingue la teoría del capital humano, la perspectiva del matching theory, la teoría de la movilidad ocupacional, el modelo de competencia y la teoría de la asignación. Además, podemos contemplar el concepto credencialismo que Collins (1979) acuñó para explicar cómo la creciente demanda y el uso de credenciales para garantizar el acceso a los niveles más altos de la sociedad puede contribuir a la inflación de su valor. Hay otros autores que suscriben un credencialismo débil como en el de modelo de competencia mencionado o el modelo de señalización (Spence, 1973), que postula que los empleadores/as tienen información imperfecta sobre las habilidades productivas

5. En los 80 el Programa Regional del Empleo para América Latina y el Caribe (PREALC) adoptó este esquema para dar cuenta del persistente sector informal urbano (Vera, 2013; PREALC-OIT, 1978). 
de los individuos y toman la educación como señal. En este sentido, las credenciales educativas se utilizan en el proceso de selección para cribar a los individuos (Goldthorpe, 2014). Ortiz (2010) señala que desde el credencialismo se otorga gran importancia a la percepción de los empleadores/as sobre la productividad de los trabajadores/as, lo que hace que la educación sea considerada como una mera señal de la misma, por tanto, la sobreeducación podría ser ventajosa y relativamente permanente. Gil et al. (2017) afirman que las teorías credencialistas consideran el logro educativo como un bien posicional, lo que en un contexto de expansión educativa proporcionaría cada vez menos información a los empleadores/as sobre la productividad potencial de los empleados/as. Esto, a su vez, conduce a una disminución tanto del poder de señalización de la educación como de sus retornos en el mercado de trabajo. También afirman que la investigación actual está encontrando rendimientos decrecientes en la educación (medida por salario, clase social, ISEI o sobreeducación) debido a la expansión considerable de la educación superior desde los años setenta y la creación limitada de empleos altamente calificados.

Coincidimos con Kucel al afirmar que el término de sobreeducación es bastante engañoso, pues sugiere que una persona puede adquirir demasiada educación en su vida, y en ese caso reflejaría un exceso con respecto al trabajo desempeñado, y que no se utilizan completamente las habilidades adquiridas por el trabajador o trabajadora a través de la educación. Ortiz (2010: 47) va en esa línea al afirmar que la sobreeducación ocurre cuando la inversión en capital humano es excesiva para el trabajo que realiza el individuo en un momento determinado.

Ese es justamente el punto en que quisiéramos insistir para resaltar las implicaciones simbólicas y engañosas que entraña el término. Consideramos que el término sobreeducación no es adecuado cuando alude al hecho de «tener mucha educación para el trabajo que se está realizando" por tres motivos: uno de carácter más bien ontológico y dos prácticos. En primer lugar, nunca una persona puede estar sobreeducada, no lo está porque la educación es un bien invaluable para mejorar la calidad de vida en todos los ámbitos de nuestro quehacer, que supera por lejos el ámbito laboral. El trabajo es uno de los aspectos de la vida, central, pero el sistema educativo no tiene por objetivo solo la inserción laboral de sus egresados, sino más bien juega un papel fundamental en el desarrollo humano y profesional de una persona. En segundo lugar, desde un punto de vista práctico con implicaciones de política pública, si la sobreeducación es considerada un problema, la solución fácil y errónea sería educar menos. Este debate es el que genera el concepto y sobre todo es amplificado por los medios de comunicación, donde las voces que se levantan consecuentemente son a favor de recortar los recursos públicos destinados a la educación superior. Se trata de una medida desafortunada de un concepto mal nominado y, por ende, mal comprendido. En tercer lugar, el concepto mal nominado de sobreeducación conduce al ocultamiento de lo que consideramos el problema real. Este está vinculado al mercado de trabajo, al modelo de empleo y a la limitada capacidad de absorción de fuerza de trabajo, dada una estructura productiva con capacidad limitada de incorporar innovación y 
tecnología, lo que conduce a limitaciones en la generación de puestos de alta calificación para que estos contribuyan a expandir las fronteras de producción de la economía en un contexto de apreciación de la educación. Como afirman Martín-Artiles et al. (2017), son las grandes empresas en mayor medida las que incorporan formación como un elemento de mejora de la competitividad, innovación tecnológica y organizativa, la mejora del proceso y la mejora en el producto, entre otros, mientras que las pequeñas empresas son intensivas en mano de obra y generan puestos de trabajo de baja cualificación, por tanto, invertir en formación representa un coste. En un contexto como el español y el argentino, con un sistema productivo con un amplio predominio de pequeñas y medianas empresas en sectores poco productivos, se reproduce un fenómeno estructural que conduce al anclaje económico y a la imposibilidad de cambiar la situación de una parte importante de puestos de trabajos que demandan una «subocupación» de la fuerza de trabajo educada.

El éxito del concepto sobreeducación ganó terreno a uno menos extendido, pero tal vez más acertado para su interpretación, que es el de sobrecualificación (overskilling), acuñado por McGuinness y Wooden (2007). No obstante, nosotros consideramos que el concepto que sería más adecuado para identificar la relación de una persona que tenga más cualificación en términos de conocimientos, habilidades o competencias que los que el puesto de trabajo requiere sería el de subocupado. Con ello se destacaría la noción de que la persona puede estar en un puesto mejor, pero que, por circunstancias diferentes, y aquí entrarían en juego todas las teorías citadas, en el momento de la observación, ocupa un lugar que subutiliza sus potencialidades y conocimientos. En términos agregados, nos situaríamos ante un modelo de empleo que finalmente infrautiliza su fuerza de trabajo. ${ }^{6}$

En el estudio de este fenómeno destacaremos finalmente que numerosos trabajos se han dedicado a analizar las diferentes formas de medir la sobreeducación aplicando diversas metodologías. Kucel (2011) revisa 52 trabajos al respecto. Para España, Marqués-Perales y Gil-Hernández (2015) utilizan la sobreeducación para referirse a los que tienen un título universitario (ISCED 5-A) y no están empleados/as en una ocupación comprendida entre los dígitos 11 y 34 de la ISCO-88, que asciende al 24\%. Martínez-García (2017), además de proponer los tres indicadores utilizados en esta literatura (objetivo, subjetivo y estadístico), explora dos medidas con los datos del PIAAC (Programa Internacional de Evaluación de las Competencias de la Población Adulta). Para la población ocupada entre 25 y 65 años, los resultados obtenidos son: 14\% de sobrecualificación objetiva, $21 \%$ la subjetiva de título educativo, $14 \%$ de sobrecualificación estadística, $15 \%$ de sobrecualificación tanto en lectura como en matemáticas.

6. Y que es diferente al concepto subempleo que utiliza la OIT para referirse a las personas que durante la semana de referencia trabajan o tienen empleo, y desean y están disponibles para trabajar mejor o más adecuadamente. El subempleo entonces se determina comparando la situación de empleo actual de una persona con una situación alternativa de empleo, es decir, una situación de empleo que los trabajadores/as desean y están disponibles para desempeñar (Mata, 1999). 


\subsection{Hipótesis}

Planteamos una hipótesis general y dos hipótesis específicas. Entendemos que los procesos de producción de las empresas se inscriben en estrategias de segmentación con políticas de flexibilización y de subcontratación que permiten afrontar las exigencias de competitividad controlando los costes y las demandas de los trabajadores/as (Miguélez, 2004; Alòs, 2008; Banyuls y Recio, 2017). Así, como resultado, se combinan en mayor o menor medida, variando según el sector de la economía y el contexto de empresa particular, la existencia de trabajos flexibles con alta rotación cubiertos mediante contratación temporal que tienden a tener condiciones de trabajo precarias, frente a trabajos centrales para la producción con baja rotación cubiertos con contratación indefinida y empleos de mayor calidad, y estos también con diferencias internas relevantes.

En este sentido, nuestra hipótesis general establece que no existe un único mercado de trabajo que ajuste oferta y demanda. Por el contrario, se diferencian diversos segmentos que estructuran posiciones jerárquicas en el mercado laboral en correspondencia con ciertos perfiles específicos de la oferta de trabajo: género, edad, origen inmigrante o niveles educativos. Dichos segmentos se diferencian, en términos duales, entre un segmento primario de empleos de calidad, caracterizados por la estabilidad y niveles medios y altos de cualificación, y un segmento secundario donde la precariedad del empleo y los bajos niveles de cualificación son definitorios. A su vez, en cada segmento cabe introducir especificidades y diferencias internas de mejores o peores condiciones laborales. En el segmento primario, cabe diferenciar en su interior dos perfiles primordiales: un segmento primario superior, de altos niveles ocupacionales y mejores condiciones de empleo, y un segmento primario inferior, de niveles de cualificación intermedios, ambos con el rasgo de la seguridad laboral. En el segmento secundario cabe identificar asimismo posiciones extremas.

Este proceso general de segmentación del trabajo se moldea bajo condiciones históricas, institucionales y culturales distintas que explicarían de forma específica la configuración de aquellos mecanismos de división, entendida como una dinámica general que se puede darse en contextos sociales distintos. En este sentido, planteamos, no obstante, que cabe esperar estructuraciones similares del mercado de trabajo entre ambos países. De manera específica, proponemos aportar evidencias de una hipótesis de trabajo en términos comparativos entendiendo que los mecanismos de desigualdad que operan en la estructuración del mercado de trabajo en España y Argentina, con las singularidades propias de cada sociedad, son similares en sus resultados y se reflejan en un patrón similar de segmentación del mercado laboral.

Finalmente, otra hipótesis específica en términos de la relación de la segmentación del empleo con el nivel educativo de la fuerza de trabajo postula que cabe esperar una asociación positiva entre la calidad del empleo y el nivel educativo de los trabajadores/as: a mayor nivel educativo (años de escolaridad), mayor nivel en la escala de ocupaciones. No obstante, la expansión educativa de los últimos años, sobre todo en el caso de España, ha comportado alcanzar altos niveles de educación formal que no se han visto 
correspondidos linealmente por un crecimiento en la demanda de los puestos de trabajo más cualificados. En nuestro planteamiento, entendemos que, más que un debilitamiento de las credenciales educativas, lo que se produce es una falta de capacidad de absorción de la mano de obra calificada dada la estructura productiva anclada de ambos países, es decir, donde se reproduce una parte importante de la economía con baja productividad, arraigada y relativamente inmóvil en el tiempo, y que este fenómeno de desajuste, sobre todo teniendo en cuenta el nivel educativo universitario, se produce en mayor medida en España que en Argentina, dada la importante expansión educativa experimentada en el primer país. ${ }^{7}$

\subsection{Operativización del modelo}

Nuestro modelo de análisis de segmentación se circunscribe a un estudio comparativo estático en el conjunto de la población ocupada asalariada. Por otra parte, se adopta un modelo de análisis que tiene en cuenta la perspectiva del empleo y no la del trabajo, entendiendo que la segmentación del trabajo, originada desde el lado de la demanda en el contexto de una organización de la producción y del trabajo, con funciones y cualificaciones efectivas observables en realidades microsociales de los puestos de trabajo, se traduce, en términos de características contractuales y condiciones de empleo, en la configuración de una estructuración agregada de la segmentación de carácter macrosocial. En esa generalización intervienen los elementos institucionales, las pautas sectoriales, el marco de relaciones laborales, el vínculo con la esfera reproductiva y otras instancias mesosociales que no tratamos en el análisis.

En nuestro modelo de segmentación, ajustado a las bases de datos con las que contamos, consideramos las interrelaciones de diversas dimensiones de caracterización de las desigualdades en el empleo, contraponiendo diversos indicadores desde el punto vista de la demanda y de la oferta de fuerza de trabajo (tabla 1). Las dimensiones que definen el lado de la demanda son: la seguridad, como una dimensión de la estabilidad y precarización del empleo; la cualificación, que diferencia niveles ocupacionales o categorías profesionales formales ${ }^{8}$; la dimensión salarial, como indicador de la calidad del empleo, y, por último, diversas características de las empresas que contextualizan el marco de relaciones sociales y organizacional donde se dan los empleos —el tamaño

7. En el caso español, de hecho, se produce un fenómeno de expansión educativa que permite la ocupación de una parte significativa de fuerza de trabajo más cualificada en algunos sectores de la economía tecnológicamente avanzados, pero al mismo tiempo — para una parte de la población autóctona y la de origen inmigrante- crece también la ocupación menos cualificada en los sectores más intensivos en mano de obra. Se genera así un proceso de polarización de la estructura de clases (Bernardi y Garrido, 2008; Molina y López-Roldán, 2015; Fachelli y López-Roldán, 2017).

8. Como indicador de la cualificación, se emplea la Clasificación Internacional Uniforme de Ocupaciones, que mide de forma jerárquica las características similares de las tareas y cometidos de los empleos y la capacitación necesaria para desempeñarlas (competencias), junto con el desempeño de funciones de supervisión. 
Tabla 1. Dimensiones e indicadores del modelo de segmentación del empleo*

\begin{tabular}{|c|c|}
\hline \multicolumn{2}{|r|}{ Caracterización de la demanda de empleo } \\
\hline Dimensión & Indicadores / Variables \\
\hline \multirow[t]{3}{*}{ Seguridad } & Tipo de contrato y duración: indefinido, $>6$ meses, $<6$ meses, informal \\
\hline & Tipo de jornada: tiempo completo, tiempo parcial \\
\hline & Tiempo en la empresa: agrupación en meses-años \\
\hline \multirow[t]{2}{*}{ Cualificación } & Nivel ocupacional: agrupación de los niveles ocupacionales \\
\hline & Supervisión: dirección, mando, encargado/a, empleado/a \\
\hline \multicolumn{2}{|c|}{ Ingresos salariales Deciles salariales: decil 1 a decil 10} \\
\hline \multirow[t]{3}{*}{$\begin{array}{l}\text { Caracterización } \\
\text { de la empresa }\end{array}$} & $\begin{array}{l}\text { Sector de actividad: primario, } 3 \text { industrias, construcción, comercio, } \\
\text { transporte-comunicaciones, financiero-profesional, administración pública, } \\
\text { otros servicios }\end{array}$ \\
\hline & Titularidad de la empresa: pública, privada \\
\hline & Tamaño de la empresa: agrupación según el número de trabajadores/as \\
\hline \multicolumn{2}{|r|}{ Caracterización de la oferta de empleo } \\
\hline Dimensión & Indicadores / Variables \\
\hline Género & Sexo: varón, mujer \\
\hline Edad & Edad: agrupación por intervalos de edad \\
\hline Inmigración & Nacionalidad: nacional, extranjero \\
\hline Educación & Nivel educativo: primaria, secundaria, superior \\
\hline
\end{tabular}

de la empresa, el sector y la titularidad—. Desde el lado de la oferta, se consideran cuatro dimensiones de caracterización: el género, la edad, la inmigración y la educación.

\subsection{Fuentes de datos y metodología de análisis}

Las ocho dimensiones con las que estructuramos las posiciones desiguales en el mercado de trabajo dan lugar a 13 variables que se construyen de forma similar con los datos disponibles para España y Argentina. En ambos casos trataremos datos de encuestas sobre la fuerza de trabajo referidos al año 2016. Para el caso de España, analizamos los datos de la Encuesta de Población Activa del Instituto Nacional de Estadística (INE), considerando un total de 30.037 trabajadores/as asalariados/as. En el caso de Argentina, tomamos el cuarto trimestre de la Encuesta Permanente de Hogares del Instituto Nacional de Estadística y Censos (INDEC), con una muestra de 17.798 individuos asalariados.

Desde el punto de vista metodológico, nuestro objetivo es triple. Por un lado, se trata de comparar los factores de estructuración del mercado de trabajo para España y Argentina y determinar el grado de similitud o disimilitud de los perfiles de segmentación del empleo de ambos países. Por otro, se busca 
obtener una variable de segmentación del mercado de trabajo de cada país y así comparar el grado de similitud o disimilitud de los segmentos laborales. Finalmente, nuestro análisis se completa relacionando los resultados de la tipología de segmentación con la variable de nivel educativo para dar cuenta de la subocupación, centrando la mirada en el caso específico de los graduados universitarios y comparando el número teórico de graduados universitarios que deberían situarse en el segmento primario con los efectivamente ubicados en él.

Formalmente, se trata de obtener una tipología de segmentos de empleo definidos en un espacio de atributos de 13 variables originales y 74 categorías asociadas. Para ello, aplicamos una metodología de construcción tipológica que denominamos estructural y articulada (López-Roldán, 1996), donde, principalmente, se combinan de forma secuencial dos técnicas de análisis multivariable: el análisis factorial, para analizar la relación entre las variables y sintetizarlas en un conjunto reducido de factores de diferenciación que definen los factores de estructuración del mercado de trabajo, y el análisis de clasificación, para agrupar a los individuos en un número de grupos o segmentos de empleo, los más homogéneos internamente y lo más heterogéneos entre sí. Finalmente, esa medida se compara con el nivel educativo.

Como nuestras variables son medidas todas ellas como categóricas, la técnica factorial que aplicamos es el análisis de correspondencias múltiples. Los factores obtenidos, sintéticos y medidos en una escala cuantitativa, se emplean a continuación como criterios clasificatorios en el análisis de conglomeración donde se ha aplicado un método mixto: primeramente, se procede a clasificar a los individuos según el método jerárquico ascendente Ward, o de mínima pérdida de inercia, y, posteriormente, considerando la partición del árbol de agregación en un número dado de grupos, se procede a optimizar la clasificación inicial aplicando el método de centros móviles (López-Roldán y Fachelli, 2015).

\section{Resultados}

\subsection{Análisis descriptivo de las variables}

En la tabla 1 del anexo se pueden observar las frecuencias de las variables empleadas en el análisis. La primera dimensión, la de seguridad en el empleo, considera, en primer lugar, el tipo de contrato y la duración, donde destaca que España tiene 15 puntos más de asalariados/as con trabajos indefinidos que Argentina. Esta diferencia se explica, en particular, por un rasgo definitorio que distingue ambos mercados laborales como es la existencia de un importante sector de trabajo informal en el país latinoamericano que alcanza el $24 \%$ del empleo asalariado, por tanto, de una relación de empleo que se corresponde en general con un trabajo precario y carente de derechos reconocidos. Esta ausencia de contrato unido al $15 \%$ de temporalidad supone una cota de mayor nivel de inseguridad contractual que refleja este indicador: del 39\%, que contrasta con el $24 \%$ que resulta para el caso español.

En esta primera dimensión, consideramos también el tiempo en la empresa: la antigüedad laboral entre 0 y 1 año es similar: del $17 \%$ en ambos países. 
Argentina tiene, en general, menos antigüedad en su fuerza laboral, lo cual es producto en parte de un efecto demográfico, al tener una población más joven que la de España, donde el 48\% tiene más de 5 años de antigüedad. En el caso español, la proporción de población trabajadora que supera los 4 años de antigüedad asciende al $70 \%$.

En tercer lugar, tuvimos en cuenta como indicador de empleo estándar, desde la dimensión de seguridad, el tipo de jornada, diferenciando entre tiempo completo y parcial. En España el porcentaje de empleo a tiempo completo es algo superior, del 83\%, mientras que en Argentina es del 78\%.

Por lo que se refiere a la segunda dimensión de cualificación, los datos muestran en España que la pirámide ocupacional está más sesgada hacia la cumbre, y hacia la base en Argentina, con mayor polarización en el caso español. Las categorías de directivos/as y técnicos/as y administrativos/as suman el $44 \%$ en España, mientras que en Argentina ese valor es del 26\%. Por su parte, los trabajadores/as cualificados/as (con calificación operativa) se acercan al 50\% en Argentina, mientras que son el $41 \%$ en España, en contraste con el mayor peso que tiene en Argentina el trabajo no cualificado asalariado: del 27\% frente al $14 \%$ español. Estos perfiles se complementan con un indicador adicional de la dimensión de cualificación que tiene en cuenta el desempeño de responsabilidades de supervisión del trabajo de otras personas. Consecuentemente, España muestra un mayor nivel de supervisión (15\%) que Argentina (5\%).

Con relación a los ingresos salariales, disponemos de la información agregada en deciles para ambos países.

Bajo la dimensión de caracterización de la empresa en la que se da la relación de empleo, recogemos diversas variables que reflejan el contexto organizacional y sectorial en el que se inscriben los empleos. En primer lugar, la distribución por sectores de actividad muestra una de las diferencias más importantes entre ambos países, que se produce en la dimensión de la ocupación de la administración pública, que es el mayor subsector de ocupación en los dos, pero superior en casi 6 puntos porcentuales en el caso argentino. Por el contrario, el sector del comercio y el financiero-profesional son notablemente más importantes en España que en Argentina, pues casi se duplican. También se registra en España un mayor peso de los subsectores industriales, del 16\% frente al 13\% en Argentina, y de otros servicios. Sin embargo, es algo más importante el sector de la construcción en el país latinoamericano9. Como resultado de esta distribución sectorial, la dimensión de la titularidad pública de las empresas se da por igual en ambos países y aglutina una cuarta parte del empleo. Respecto al tamaño de las empresas, atendiendo al indicador del número de trabajadores/as, las distribuciones tienen cierta similitud, en las que destaca el mayor peso que tienen las empresas más pequeñas, de 5 o menos trabajadores/as, que concentran casi el $27 \%$ de la fuerza de trabajo asalariada en

9. Cabe señalar que la EPH argentina recoge información fundamentalmente de la población urbana e infravalora el peso del sector primario, por lo que su introducción haría variar algo los valores comentados. 
Argentina y el 18\% en España. El resto de los porcentajes no presenta grandes diferencias entre ambos países.

Con relación a las variables de caracterización de la oferta de empleo, se observan diversas diferencias entre ambos países. En primer lugar, la variable sexo muestra para el caso de España una distribución de asalariados y asalariadas equilibrada, cercana al 50\%, mientras que en Argentina las mujeres tienen una inserción laboral que representa el $45 \%$ del total de la población asalariada.

Los datos de distribución de las edades evidencian un mercado laboral argentino con un mayor peso de los más jóvenes y que la entrada es más tardía en el mercado de trabajo español. En la franja de edad entre 16 y 24 años, se incluye el $13 \%$ de la fuerza laboral asalariada, mientras que este porcentaje representa el 5\% en el caso de España. Lo mismo sucede con las dos franjas siguientes de edades más jóvenes para invertirse en favor de España a partir de los 35 años, mostrando el mayor envejecimiento de la pirámide poblacional asalariada, si bien en la última franja etaria se vuelve a igualar o invertir ligeramente.

El indicador de nacionalidad nos revela otro rasgo de la oferta laboral, donde podemos observar en este caso un mayor peso laboral de las personas de origen extranjero en España, de casi el 8\% versus el poco más del 5\% de Argentina.

Por último, la información del nivel educativo pone de manifiesto la desigual distribución entre ambos países: la mayor expansión educativa en España se refleja en un bajo porcentaje de población con niveles educativos de primaria y un mayor porcentaje en los niveles superiores de educación. Entre la población asalariada, casi el 31\% tiene una titulación universitaria, valor que se reduce al 14\% en Argentina, en que destaca el dato de un 33\% de población trabajadora con estudios de primaria.

De esta lectura se concluye pues la existencia de diferencias destacables en los mercados laborales asalariados español y argentino, con mayores niveles de cualificación y menor precarización en España con relación al país austral. La cuestión que se suscita a continuación es cómo se incardinan ese conjunto de indicadores para configurar factores de desigualdad de posiciones en el mercado de trabajo, en qué medida se asemejan ambos países, y a qué segmentos de empleo dan lugar.

\subsection{Factores de segmentación del empleo}

En un primer análisis buscamos obtener los principales factores de diferenciación de la fuerza de trabajo asalariada a partir de la interacción del conjunto de 13 variables elegidas como espacio social de expresión de la dinámica de segmentación del empleo. Estos factores sintéticos se obtienen combinando las variables categóricas originales mediante la aplicación de un análisis factorial de correspondencias múltiples. Con él podemos reducir de forma parsimoniosa a unos pocos factores significativos que acumulan la información multidimensional inicial de las categorías activas de las 13 variables que definen simultá- 
neamente las características de los empleos, tanto desde el punto de vista de la demanda como de la oferta. Como resultado de nuestro análisis, tenemos dos factores principales en ambos países que explican el 86\% de la varianza en el caso de España y el 88\% en el caso de Argentina. Estos dos factores, o dimensiones sintéticas y significativas de la información, expresan un patrón general de comportamiento similar en ambos países que pasamos a comentar (ver los gráficos 1 y 2 adjuntos, y las tablas 2 y 3 del anexo).

El primer factor principal acumula la mayor parte del poder explicativo de la información contenida en las variables originales: el 71\% en España y el 72\% en Argentina. Se trata de un eje fundamental de segmentación del empleo para los dos países, con una coincidencia de rasgos donde se opone, por un lado, el perfil de los empleos atípicos de peor calidad, es decir, los más inseguros por contratación temporal de corta duración, los basados en relaciones laborales informales, los que tienen jornadas a tiempo parcial, entre trabajadores y trabajadoras jóvenes que llevan poco tiempo en la empresa realizando los trabajos menos cualificados, sin responsabilidades de supervisión y con bajos niveles de estudios. En consecuencia, se corresponden con los empleos que tienen los más bajos niveles salariales del mercado de trabajo. Son empleos característicos de las pequeñas empresas, de titularidad privada, especialmente del sector de otros servicios, construcción y el comercio (también del sector primario en el caso español). Es el perfil que define la polaridad más precaria y devaluada del mercado laboral, donde se posiciona una parte de la población autóctona, la más joven y menos cualificada, pero sobre todo la población de origen inmigrante.

Por otro lado, se contrapone el perfil del empleo seguro y de calidad, caracterizado por la formalización de contratos indefinidos en jornadas completas y donde tienen lugar las relaciones laborales con mayor antigüedad en la empresa. Se corresponden con puestos de trabajo en los que se desempeñan funciones de niveles medios y altos de cualificación, por tanto, a los que se asocian responsabilidades de supervisión y niveles educativos medios y altos. Como resultado, es el perfil al que se asocian los mayores niveles salariales. Se dan sobre todo en empresas medianas y grandes, de forma destacada en el sector público, aunque también en los sectores de la industria y parte de los servicios: administración pública, educación, sanidad, transporte-comunicaciones. Es también el caso del subsector financiero y profesional para Argentina, aunque no lo es tanto para España, pues se sitúa en el centro del gráfico atraído por la presencia de rasgos del extremo más inseguro. La estabilidad laboral que emerge de esta polaridad de la primera dimensión se corresponde a su vez con el perfil de más edad de la fuerza de trabajo de ambos países, así como con la presencia dominante de la población autóctona.

Concluimos, pues, la configuración de un factor principal de diferenciación de la población asalariada que podemos identificar como de segmentación laboral al contraponer un perfil de segmento primario, de calidad, con seguridad, cualificación y mejor remuneración, de calidad en el empleo, por tanto, contra un perfil de segmento secundario, caracterizado por la inseguridad, la baja cualificación, la baja remuneración y la mayor desprotección, de precariedad laboral. 
Gráfico 1. Espacio social de segmentación del mercado de trabajo español

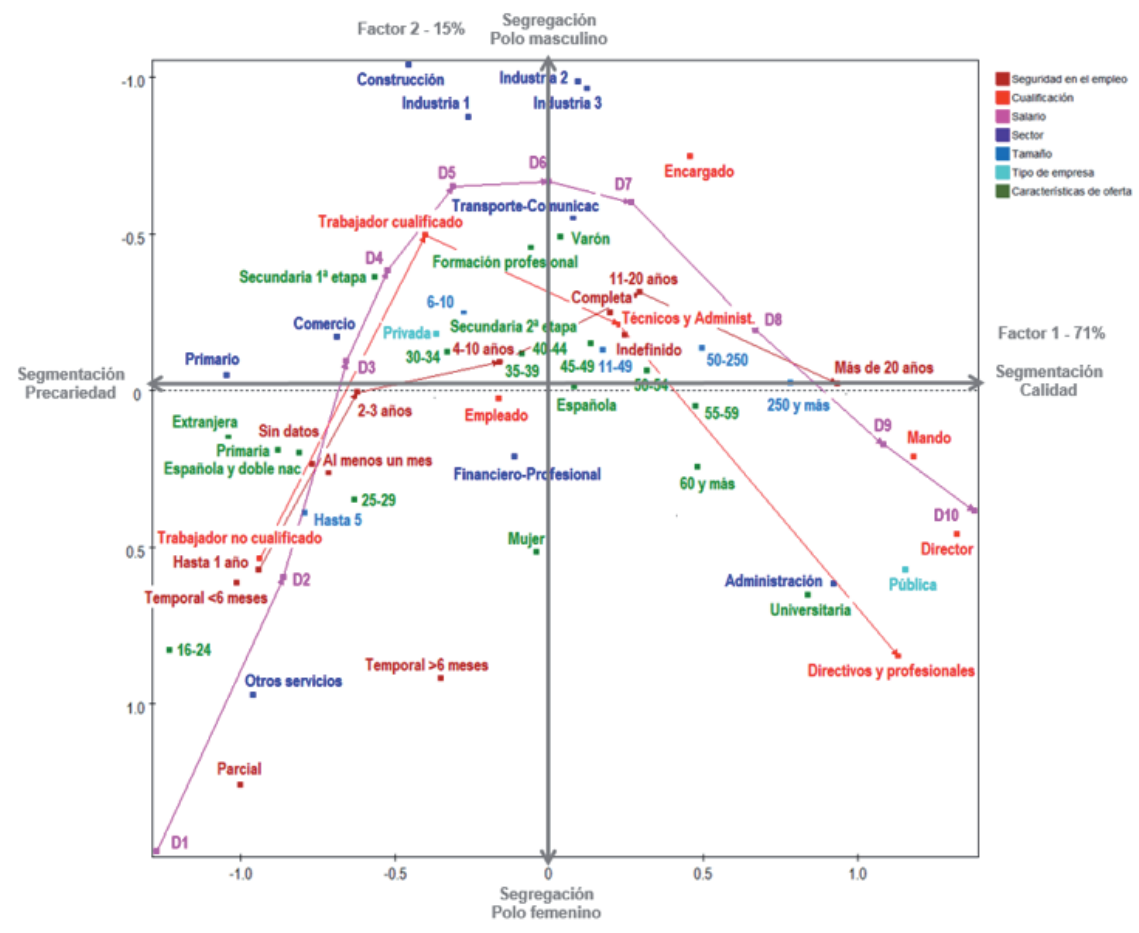

Fuente: elaboración propia a partir de la EPA de 2016.

Un segundo factor, con un peso mucho menor, del $15 \%$ en el caso de España y del 16\% para Argentina, matiza el primer factor para diferenciar las posiciones intermedias de las extremas que expresa este. Esta contraposición se manifiesta en el gráfico factorial dibujando una nube de puntos con una forma parabólica, identificando el conocido efecto Guttman del análisis de correspondencias. Así pues, en un extremo del eje factorial encontramos el perfil de los niveles ocupacionales intermedios de trabajadores cualificados $u$ operativos, característicos en particular de las empresas privadas de la industria, la construcción y el transporte. Son rasgos compartidos por ambos países, la diferencia radica en que en el caso español se trata de empleo estable, mientras que en el argentino incluye también la informalidad.

En el otro extremo del segundo eje factorial, separados en el primero, pero ocupando un mismo espacio desde la mirada del segundo, nos encontramos simultáneamente en ambos países empleos seguros e inseguros, altos y bajos niveles profesionales, altos y bajos ingresos, sector público y otros servicios.

Esta confluencia en esta polaridad del segundo factor adquiere su sentido por la asociación que mantiene con la variable sexo, que es neutral en el primer 
Gráfico 2. Espacio social de segmentación del mercado de trabajo argentino

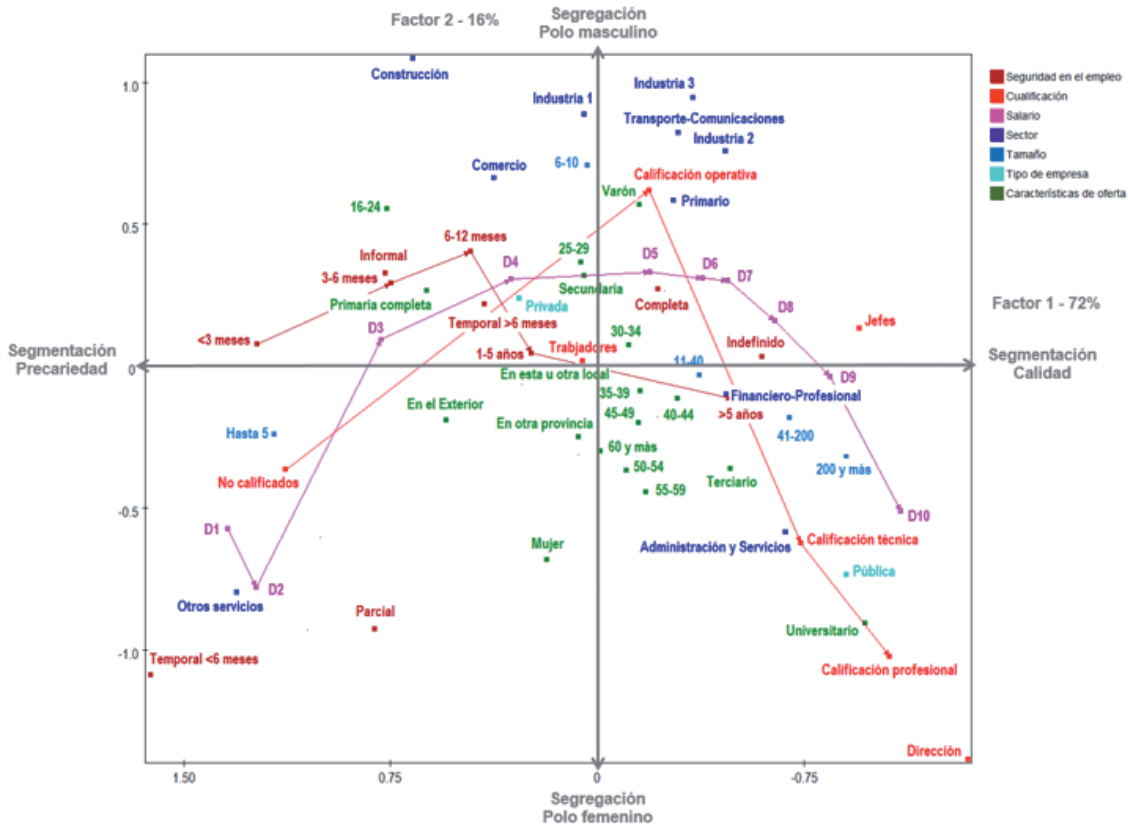

Fuente: elaboración propia a partir de la EPH de 2016.

factor y que emerge en este segundo para expresar una dimensión de segregación ocupacional: en el polo de niveles intermedios se ocupan los varones preferentemente y en el polo de los extremos las mujeres, que están ocupadas de forma polarizada tanto en bajos como en altos niveles ocupacionales. Además, destaca la asociación que se da entre jornadas completas de los varones y jornadas parciales de las mujeres. La particularidad del caso español es que la contraposición de niveles medios y extremos se corresponde por igual con la distribución de la edad, contraponiendo las edades intermedias respecto de los jóvenes y mayores. En el caso argentino no se da tan claramente y tienden a asociarse las edades jóvenes y medias con el polo intermedio y las mayores con el polo de los extremos. Esta oposición entre niveles intermedios y el resto remite también a un factor específico de segmentación, pues contribuye a establecer la distinción entre el perfil de segmento primario inferior frente al resto, y sobre todo frente al segmento primario superior.

En resumen, mediante el análisis factorial concluimos que se estructuran posiciones desiguales en el mercado de trabajo asalariado en base a dos factores principales de diferenciación del empleo, tanto en España como en Argentina, y que identificamos como un primer eje principal de segmentación y uno secundario de segregación. Cabe subrayar que, empleando los mismos indicadores de segmentación del empleo en ambos países, desde la particularidad de 
cada formación social, emergen realidades laborales de desigualdad coincidentes en contenido y magnitud.

Con estos resultados, nos planteamos seguidamente cómo se expresan estos factores de desigualdad laboral en términos de grupos de trabajadores y trabajadoras que comparten unos mismos perfiles en ese espacio laboral, es decir, cuáles son los tipos o segmentos de empleo que se configuran. Para ello aplicaremos un análisis de clasificación.

\subsection{Tipologías de segmentación del empleo}

Teniendo en cuenta como criterios de clasificación los dos factores de segmentación y segregación que emergen del análisis de dimensionalización, procedimos a ejecutar un análisis clasificatorio para obtener una tipología de segmentos de empleo para España y Argentina. Tras la realización de múltiples ejercicios de validación en términos de estabilidad de resultados, relevancia sustantiva y capacidad interpretativa, se concluyó la configuración de una tipología para cada país con cuatro tipos de estratificación del mercado de trabajo y, como veremos, resultado que nos permite tipificar las desigualdades sociales en el mercado de trabajo tanto en términos duales como en forma de una tríada de segmentos.

En los gráficos 3 y 4 adjuntos y las tablas 3 y 4 del anexo se pueden consultar los datos descriptivos de los perfiles de cada tipo de ambos países que nos ayudan a dar identidad a los segmentos de empleo. Pasamos a continuación a resumir sus principales rasgos en el orden jerárquico que emerge desde el segmento inferior al superior.

Para España, el tipo 1 conglomera el 15\% de los casos con el perfil de segmento secundario más extremo que hemos denominado inferior. Comparte con el siguiente tipo los bajos niveles de cualificación y la inseguridad del empleo, y su rasgo definitorio es el de congregar a las mujeres (78\% del tipo) con el menor nivel de ingresos (el 59\% está en el decil 1) debido, en particular, a que el $80 \%$ del grupo está contratado a tiempo parcial. Se trata de empleos feminizados en empresas pequeñas privadas especialmente de otros servicios y financiero-profesional. Poseen en general un perfil de personas jóvenes con bajo nivel educativo y una mayor presencia de la población de origen inmigrante (17\%).

Por su parte, en el tipo 2, con el $24 \%$ de las personas asalariadas, predomina igualmente la ocupación insegura y poco cualificada en empresas privadas de pequeño tamaño, características del comercio, de otros servicios, de la construcción, del financiero-profesional y del sector primario donde se dan también los más bajos niveles salariales, si bien más atenuados que en el caso anterior, repartidos entre los deciles 1 a 5 . Se trata de relaciones laborales sin antigüedad en la empresa, de personas jóvenes con bajos niveles de estudios o secundarios, con una mayor presencia femenina (53\%) y de la población extranjera (15\%).

El tipo 3, con el 33\% de los trabajadores/as asalariados/as, reúne el empleo característico del segmento primario inferior. Esto es, se trata de empleos esta- 
bles a jornada completa ocupados por trabajadores/as cualificados/as y técnicos/ as-administrativos/as de empresas privadas en los sectores de la industria, la construcción, el comercio y transporte-comunicaciones principalmente, con antigüedad en las empresas medianas o grandes donde se emplean. Se sitúan en los niveles medios de ingresos, entre el decil 4 y 8 . Es un perfil de empleo masculinizado (el $75 \%$ son varones) con niveles educativos de secundaria y formación profesional, en edades de entre 30 y 54 años, con baja presencia de personas inmigrantes.

Finalmente, el tipo 4 representa el $28 \%$ del empleo asalariado que identificamos como segmento primario superior. Reúne las mejores condiciones de empleo: seguridad, alta cualificación, responsabilidades de supervisión, altos niveles salariales y antigüedad en la empresa. Son características presentes sobre todo en empresas grandes y de la administración pública específicamente (70\%). El perfil de estos asalariados/as es el de los autóctonos/as de mayor edad, de 45 años en adelante, con mayor presencia femenina (el $57 \%$ son mujeres) y altos niveles de formación (el $75 \%$ son universitarios).

Gráfico 2. Espacio social de segmentación del mercado de trabajo argentino

España

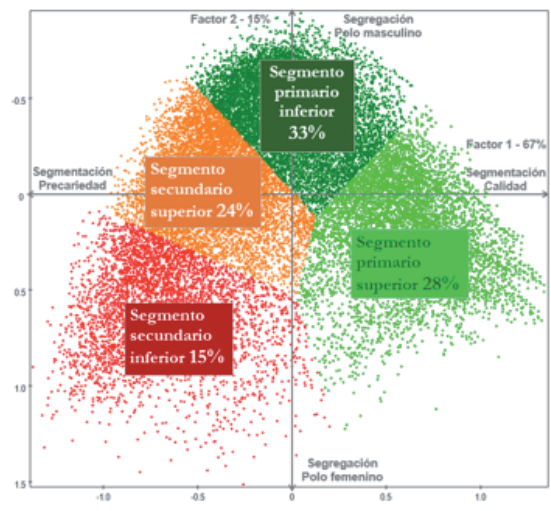

Argentina

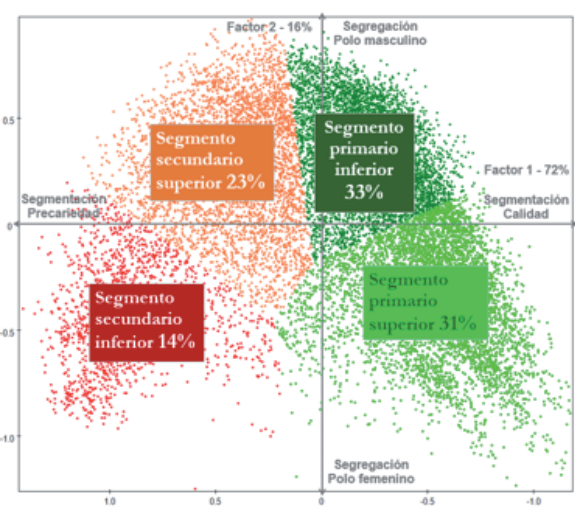

Fuente: elaboración propia a partir de la EPA (España) y de la EPH (Argentina) de 2016.

Para Argentina, el tipo 1 supone el 14\% del trabajo asalariado y, de forma coincidente con el resultado para España, se caracteriza por la precariedad del empleo en términos de seguridad, con los más bajos ingresos. Como segmento secundario inferior, congrega los empleos de baja cualificación en el sector de otros servicios en empresas privadas pequeñas ocupados por mujeres $(90 \%)$ en jornadas a tiempo parcial $(70 \%)$, con contratos eventuales $(59 \%)$ o informales (36\%). A semejanza del mismo tipo español, sobresale la proporción de población de origen inmigrante, pero difiere en la caracterización según la 
edad; en el caso argentino no es un rasgo propio de la juventud, sino que tiende a polarizarse entre personas muy jóvenes y las más mayores.

El tipo 2, con el 23\% de los casos, identifica, de forma equivalente al tipo español, al segmento secundario superior. Los rasgos de inseguridad y la baja cualificación son absolutamente dominantes: $59 \%$ de la informalidad, $19 \%$ de la temporalidad contractual, $42 \%$ en ocupaciones no calificadas y $52 \%$ en calificación operativa. En correspondencia, tienen salarios bajos que se mueven entre el decil 1 y el 4 . A diferencia del tipo español, predominan los varones $(68 \%)$ y se ocupan en empresas privadas pequeñas de la construcción, el comercio y también del sector industrial 1, en algunos casos con cierta antigüedad en la empresa. Son personas fundamentalmente jóvenes con bajo nivel educativo.

El tipo 3 argentino representa el 33\% del empleo asalariado, y lo reconocemos de forma similar al tipo español como segmento primario inferior. Coincide en ocupar a trabajadores/as indefinidos/as (87\%) a jornada completa con la categoría de calificación operativa $(78 \%)$ en empresas privadas de la industria 2 y 3 , el comercio y transporte y comunicaciones, que tienden a ser medianas o grandes. Sin embargo, no muestra como rasgo destacable la antigüedad en la empresa del caso español, por lo que se distribuye de forma similar al conjunto de la población asalariada. Sí que se sitúa en los niveles medios de ingresos, entre el decil 5 y 8 . Comparte asimismo la masculinización (el $80 \%$ son varones), el predomino del nivel de estudios secundarios y de las edades intermedias.

Por último, el tipo 4 se corresponde con el segmento primario superior, con un peso del 31\%. La descripción de su perfil redunda en los rasgos de su homólogo español, identificando la mayor calidad de empleo: contratación indefinida, calificación técnica o profesional, los mayores ingresos, la mayor antigüedad en la empresa. Coincide en tratarse de empresas grandes y en el predominio de la ocupación en la administración pública y servicios de apoyo (79\%), junto con el sector financiero-profesional. Su perfil es también el de autóctonos a partir de 35 años de edad con un predominio de la población femenina, más acentuado que en el tipo español (el 63\% son mujeres), y con alto nivel formativo. Este último rasgo difiere con relación a España por su diferente composición; en Argentina el segmento se reparte entre un 38\% de universitarios y un 36\% de nivel educativo de terciario.

Constatamos, pues, el alto grado de similitud en la estructuración del mercado de trabajo español y argentino, con una tipología de segmentos de empleo que tipifica de forma coincidente las posiciones desiguales de la ocupación asalariada, incluso en magnitudes parecidas. En la tabla 2 se presentan los cuatro tipos que emergen de nuestro análisis y que hemos identificado como segmento primario, separando el superior del inferior, y segmento secundario, distinguiendo también un nivel superior e inferior. Esta división del empleo asalariado en cuatro tipos revela igualmente la segmentación del mercado laboral en términos duales, y agrupa los dos segmentos primarios y los dos secundarios, o en términos de una tríada de categorías aunando los dos tipos 
Tabla 2. Distribución de la tipología de segmentación del empleo para España y Argentina según diferente número de segmentos

\begin{tabular}{|c|c|c|c|c|c|c|c|c|}
\hline $\begin{array}{c}\text { Tipología en } 4 \\
\text { segmentos }\end{array}$ & España & Argentina & $\begin{array}{c}\text { Tipología en } 3 \\
\text { segmentos }\end{array}$ & España & Argentina & $\begin{array}{c}\text { Tipología en } 2 \\
\text { segmentos }\end{array}$ & España & Argentina \\
\hline $1^{0}$ superior & $28 \%$ & $31 \%$ & $1^{0}$ superior & $28 \%$ & $31 \%$ & \multirow{2}{*}{$1^{0}$} & \multirow{2}{*}{$61 \%$} & \multirow{2}{*}{$64 \%$} \\
\hline $1^{0}$ inferior & $33 \%$ & $33 \%$ & $1^{0}$ inferior & $33 \%$ & $33 \%$ & & & \\
\hline $2^{\circ}$ superior & $24 \%$ & $23 \%$ & \multirow{2}{*}{$2^{0}$} & \multirow{2}{*}{$39 \%$} & \multirow{2}{*}{$37 \%$} & \multirow{2}{*}{$2^{0}$} & \multirow{2}{*}{$39 \%$} & \multirow{2}{*}{$37 \%$} \\
\hline $2^{0}$ inferior & $15 \%$ & $14 \%$ & & & & & & \\
\hline
\end{tabular}

Fuente: elaboración propia a partir de la EPA de 2016 para España y la EPH de 2016 para Argentina.

secundarios, como se muestra en la tabla. El hecho relevante es la confluencia de dinámicas de segmentación laboral en ambos países con los mismos rasgos generales en sus resultados y la emergencia de unos segmentos muy similares que identifican y estratifican las desigualdades en el empleo. Una cuestión relevante a plantear en futuros análisis sería avanzar sobre el estudio de las causas de estas similitudes.

\subsection{Segmentación del empleo y educación formal}

Con el fin de explorar la hipótesis específica sobre la relación entre los segmentos obtenidos en Argentina y España, y los niveles educativos, presentamos los resultados de la tabla 3 y el gráfico 4 . Observamos que globalmente se confirma que, a mayor educación formal, el trabajador o trabajadora se ubica en un segmento de mejores condiciones. Así, en España el 78\% de los trabajadores/as con primaria está ubicado en los segmentos secundarios (superior e inferior); en Argentina ese valor es del 61\%. Los asalariados/as con educación secundaria se posicionan en mayor medida en los segmentos intermedios (primario inferior y secundario superior) en ambos países, mientras que el 66\% de los que tienen formación profesional en España se encuentran en los segmentos primarios. El $82 \%$ de los trabajadores/as con terciario en Argentina se encuentra en ambos segmentos primarios.

Por su parte, respecto a la relación entre segmentación del mercado laboral y su vinculación con la educación superior, cabe realizar varias puntualizaciones. En el caso de España, las personas que tienen un grado universitario se encuentran en los segmentos primarios, con porcentajes elevados; el $69 \%$ del primario superior son universitarios, pero en menor medida que en Argentina, donde esta cifra alcanza el 86\%. Estos datos van en línea con el hecho de corroborar la hipótesis sobre la existencia de correspondencia entre niveles educacionales altos y posicionamiento en segmentos de mayor calidad. Pero al mismo tiempo revelan el desajuste y la subocupación que suponen.

El tema contextual es muy importante, dado que, como muestra el gráfico 4, entre los asalariados/as hay el 31\% de universitarios en España y el 14\% en Argentina. Esta situación diferenciada nos permite preguntarnos en qué 
Tabla 3. Distribución de la tipología de segmentación del empleo según los niveles educativos en España y Argentina

\begin{tabular}{|c|c|c|c|c|c|}
\hline \multicolumn{6}{|c|}{ España } \\
\hline \multirow[b]{2}{*}{ Nivel educativo } & \multicolumn{4}{|c|}{ Segmento de empleo } & \multirow{2}{*}{$\begin{array}{c}\text { \% Total } \\
\text { educación }\end{array}$} \\
\hline & $1^{\circ}$ superior & $1^{\circ}$ inferior & $2^{\circ}$ superior & $2^{\circ}$ inferior & \\
\hline Primaria & $2,8 \%$ & $19,5 \%$ & $45,0 \%$ & $32,7 \%$ & $4,8 \%$ \\
\hline Secundaria $1^{a}$ etapa & $3,9 \%$ & $43,8 \%$ & $34,1 \%$ & $18,2 \%$ & $27,0 \%$ \\
\hline Secundaria $2^{\mathrm{a}}$ etapa & $16,9 \%$ & $39,4 \%$ & $28,1 \%$ & $15,6 \%$ & $23,4 \%$ \\
\hline Formación profesional & $14,5 \%$ & $52,0 \%$ & $22,7 \%$ & $10,7 \%$ & $13,9 \%$ \\
\hline Universitario & $68,5 \%$ & $12,1 \%$ & $9,8 \%$ & $9,7 \%$ & $30,8 \%$ \\
\hline \% Total segmentación & $28,3 \%$ & $33,0 \%$ & $24,2 \%$ & $14,6 \%$ & $100 \%$ \\
\hline \multicolumn{6}{|c|}{ Argentina } \\
\hline & \multicolumn{4}{|c|}{ Segmento de empleo } & \\
\hline Nivel educativo & $1^{\circ}$ superior & $1^{\circ}$ inferior & $2^{\circ}$ superior & $2^{\circ}$ inferior & educación \\
\hline Primaria & $6,6 \%$ & $32,7 \%$ & $35,6 \%$ & $25,1 \%$ & $33,5 \%$ \\
\hline Secundaria & $17,6 \%$ & $45,8 \%$ & $24,5 \%$ & $12,0 \%$ & $33,2 \%$ \\
\hline Terciario & $55,3 \%$ & $26,5 \%$ & $12,3 \%$ & $5,9 \%$ & $19,8 \%$ \\
\hline Universitario & $86,4 \%$ & $10,1 \%$ & $1,9 \%$ & $1,6 \%$ & $13,5 \%$ \\
\hline \% Total segmentación & $13,8 \%$ & $22,8 \%$ & $32,8 \%$ & $30,7 \%$ & $100 \%$ \\
\hline
\end{tabular}

España: $\mathrm{N}=30.037$, Chi-cuadrado=12.097 (sig. $=0,000$ ), $\mathrm{V}$ de Cramer $=0,366$.

Argentina: $\mathrm{N}=17.738$, Chi-cuadrado $=7.332$ (sig. $=0,000$ ), $\mathrm{V}$ de Cramer $=0,371$.

Fuente: elaboración propia a partir de la EPA de 2016 para España y la EPH de 2016 para Argentina.

medida existe una devaluación de las credenciales educativas, si seguimos el postulado de la teoría credencialista. Por un lado, cabe afirmar que deberíamos falsarlo, pues los universitarios están mayormente ubicados en los segmentos correspondientes a mayor calidad de la ocupación, sobre todo en el caso de Argentina. Por otro lado, si de la máxima cualificación formal, los universitarios, cabe esperar una inserción laboral al más alto nivel, la conclusión, mirando el lado de la demanda y no el de la oferta, la supuesta devaluación no es más que la expresión de la incapacidad del sistema productivo para expandirse con altos niveles de innovación y productividad y de absorber, en consecuencia, una fuerza de trabajo preparada para ello, apreciada educativamente, no devaluada. Mientras el país permanece anclado en los mismos parámetros de estructura productiva dual, con una alta proporción de sectores intensivos en mano de obra poco cualificada frente a otros más cualificados, las consecuencias serán de mantenimiento de la brecha ocupacional y de la subocupación. En el caso argentino, esta situación se da en menor medida porque las tasas de graduación permiten un mayor equilibrio; en el caso español, tras la expansión educativa, el desajuste es mayor. 
Gráfico 4. Distribución de los universitarios según los segmentos de empleo en el espacio factorial
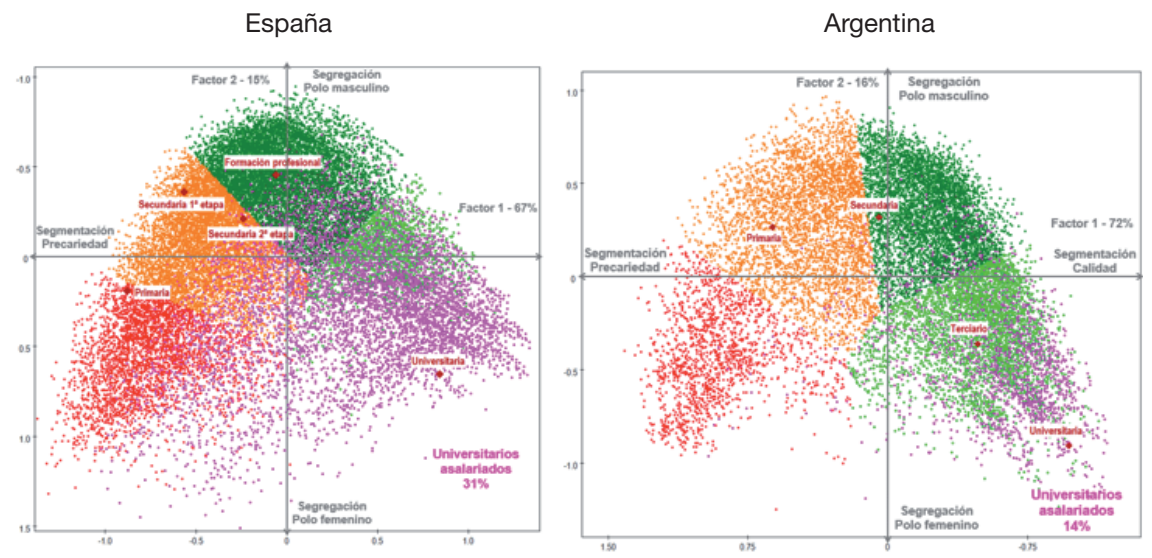

En color fucsia los asalariados/as con titulación universitaria.

Fuente: elaboración propia a partir de la EPA de 2016 para España y la EPH de 2016 para Argentina

\section{Conclusiones}

En el análisis presentado hemos podido comprobar la existencia de un patrón general común de estructuración del mercado de trabajo español y argentino en términos de segmentación, tal como planteábamos en nuestra hipótesis. Constatamos la configuración de cuatro segmentos laborales, expresables en forma de tríada o de dicotomía, que responden a los perfiles que la literatura segmentacionista argumenta. Así, se establecen dos ejes de división del conjunto del empleo asalariado. Un eje principal de segmentación opone la calidad del empleo frente a la precariedad, dimensión que diferencia, respectivamente, los perfiles del segmento primario y secundario. Un segundo eje de división nos introduce la segregación del empleo asociada a la dimensión de género, contraponiendo un perfil masculino de niveles intermedios de cualificación, de cuello azul, en la industria, frente a los empleos ocupados en mayor medida por mujeres que se polarizan entre el trabajo de mayor cualificación, de cuello blanco, especialmente del sector público, y el trabajo precario no cualificado de servicios.

La tipificación en cuatro segmentos se observa tanto en España como en Argentina, con una distribución porcentual muy similar, y sobre todo con una coincidencia de los perfiles dominantes que los describen. En ambos casos, además, hemos podido observar la correspondencia entre la estructuración del mercado de trabajo entre características tanto de la demanda como de la oferta de la fuerza de trabajo. Es importante señalar que ambas tipologías de segmentación, la española y la argentina, son la expresión relativa de las realidades laborales propias de cada territorio, por tanto, la agrupación refleja 
características con rasgos muy semejantes a pesar de los contextos de desarrollo y regulación. Ciertamente, la estructura ocupacional y la educativa difieren, y la informalidad es un fenómeno muy distintivo de la realidad argentina, pero, a pesar de estos contextos socioproductivos distintos, la estructuración de las desigualdades en el mercado laboral comparte factores de diferenciación y tipos de empleo con muchos elementos comunes en la estratificación del empleo.

$\mathrm{Al}$ analizar el nivel educativo de los asalariados y asalariadas según el segmento de empleo, se reitera la importancia de la educación y de la cualificación para alcanzar los mejores niveles ocupacionales. De esta manera, hay un encaje entre la formación y el empleo. Pero, de nuevo, no es una condición suficiente haber alcanzado un nivel educativo formal. Un mercado de trabajo que genera subocupación, que no es capaz de absorber la fuerza de trabajo más formada con puestos de trabajo acordes, genera un problema socioeconómico de primer orden. En España más que en Argentina. Particularmente, en el caso de los graduados universitarios, y con el fin de explorar la hipótesis que plantean las teorías credencialistas sobre la devaluación de las titulaciones, nuestro análisis nos lleva a concluir que no se da tanto un desajuste en la correspondencia entre educación y empleo en el mercado de trabajo, sino un desajuste estructural entre sistemas que han mostrado diferentes velocidades, entre un sistema educativo más dinámico, con una capacidad de generar capital formativo, y otro más lento y anquilosado de un sistema productivo que no genera suficientes procesos de innovación tecnológica y organizacional con la consecuente demanda de trabajo cualificado.

La segmentación, la precarización o la subocupación no son fenómenos nuevos en ninguno de los dos países. La persistencia del proceso de segmentación laboral y la consolidación de un amplio segmento secundario, una parte importante del cual se encuentra en situaciones de pobreza en el trabajo, provocan que sea un fenómeno estructural. Mujeres, jóvenes y migrantes son los colectivos característicos de un segmento secundario que se perpetúan en esa situación marginal, y generan desiguales posiciones en el mercado de trabajo y en sus condiciones de vida, especialmente en los momentos de crisis. Una realidad acuciante que requiere reformas importantes para prevenir y erradicar estas situaciones extremas, y para convertir las ocupaciones en trabajo decente con garantías para la vida social autónoma sin privaciones. El diseño de políticas pasivas y activas del mercado de trabajo debe buscar este objetivo de mejorar la calidad del trabajo y mitigar los efectos de la segmentación. Pero no serán suficientes si reproducen el modelo de empleo y la estructura productiva que lo alienta, condición sine qua non para el cambio de rumbo y para evitar la subocupación de una población más formada. Pensando en el largo plazo, la capacidad y la voluntad de imaginar reformas estructurales con otras políticas coordinadas, de inversión pública y privada, en el orden económico, social y de empleo, se convierten en una necesidad para revertir las realidades productivas y ocupacionales ineficientes y desiguales que persisten en el tiempo en ambos países. Para ese cambio de rumbo, la receta debe contemplar además, necesariamente, procesos de negociación y acuerdo entre los agentes sociales. 
Para profundizar sobre este fenómeno, será de interés orientar la futura investigación a extender los casos de estudio con otros países. Entendemos que las hipótesis que han guiado nuestra investigación orientan la mirada analítica y están sujetas a posteriores evidencias y corroboraciones que desarrollaremos en trabajos sucesivos con más análisis comparativos y explicativos. Una investigación que requiere asimismo introducir una perspectiva dinámica de análisis de los cambios en el tiempo y también de las trayectorias laborales, y abarcar el conjunto del empleo asalariado y no asalariado, así como su vínculo con la estructura productiva, la esfera reproductiva y las condiciones de vida, profundizando en los elementos comparativos institucionales de regulación laboral y de modelos de empleo.

\section{Referencias bibliográficas}

ALÓS-MonER, Ramon (2008). «Segmentación de los mercados de trabajo y relaciones laborales. El sindicalismo ante la acción colectiva». Cuadernos de Relaciones Laborales, 26 (1), 123-148.

Alós, Ramon; BENEYTO, Pere J. y JÓDAR, Pere (2017). «Reforma laboral y desregulación del mercado de trabajo». Anuario IET de Trabajo y Relaciones Laborales, 4, 73-86. $<$ https://doi.org/10.5565/rev/aiet.55>.

AlzúA, María (2009). «Are informal workers secondary workers?: Evidence for Argentina». Desarrollo y Sociedad, 63, 81-114.

Banyuls, Josep; Miguélez, Fausto; Recio, Albert; Cano, Ernest y Lorente, Raúl (2009). «The transformation of the employment system in Spain: Towards a mediterranean neoliberalism?». En: BosCH, Gerhard; LEHNDORFF, Steffen y RUBERY, Jill (eds.). European employment models in flux. A comparison of institutional change in nine European countries, 247-269. Basingstoke: Palgrave Macmillan. $<$ https://doi.org/10.1057/9780230237001_10>.

BANYULS, Josep y RECIO, Albert (2017). «Labour segmentation and precariousness in Spain: theories and evidence». En: Grimshaw, Damian; Fagan, Colette; Hebson, Gail y TAVORA, Isabel (eds.). Making work more equal: A new labour segmentation approach, 129-149. Manchester: Manchester University Press. $<$ http://www.oapen.org/search?identifier=634747>.

BECCARIA, Luis y Groisman, Fernando (2015). «Informalidad y segmentación del mercado laboral: el caso de la Argentina». Revista CEPAL, 117, 127-144. $<$ https://doi.org/10.18356/4d859903-es>.

Beck, E. M.; Horan, Patrick y TolberT, Charles M. (1978). «Stratification in a dual economy: A sectoral model of earnings determination». American Sociological Review, 43 (5), 704-720. $<$ https://doi.org/10.2307/2094545>.

BERNARDI, Fabrizio y GARRIDO, Luis (2008). «Is there a new service proletariat? Postindustrial employment growth and social inequality in Spain». European Sociological Review, 24 (3), 299-313. $<$ https://doi.org/10.1093/esr/jcn003>.

Bertranou, Fabio; Casanova, Luis; Jiménez, Maribel y Jiménez, Mónica (2014). Informality and employment quality in Argentina: Country case study on labour market segmentation. Ginebra: ILO. $<$ https://doi.org/10.2139/ssrn.2350292>. 
Boeri, T. y Garibaldi, P. (2007). «Two Tier Reforms of Employment Protection: a Honeymoon Effect?». The Economic Journal, 117 (521), 357-385. <https://doi.org/10.1111/j.1468-0297.2007.02060.x>

BosCH, Gerhard; LeHndorfF y Steffen; Rubery, Jill (eds.) (2009). European employment models in flux: A comparison of institutional change in nine European countries. Hampshire: Palgrave Macmillan. <https://doi.org/10.1111/j.1468-2338.2010.00591_3.x>.

ChÁvez-Molina, Eduardo y Pla, Jésica (2013). Desigualdad y movilidad social en el mundo contemporáneo. Buenos Aires: Editorial Imago Mundi.

Collins, Randall. (1979). The credential society. Nueva York: Academic Press.

CRAIG, Christine; RUBERY, Jill; TARLING, Roger y WiLKInSON, Frank (1982). Labour market structure, industrial organisation and low pay. Cambridge: Cambridge University Press.

DiCKENS, William T. y LANG, Kevin (1988). «The reemergence of segmented labor market theory». The American Economic Review, 78 (2), 129-134.

Doeringer, Peter B. y PiORE, Michael J. (1985). Mercados internos de trabajo y análisis laboral. Madrid: Ministerio de Trabajo y Seguridad Social.

FACHELl, Sandra y LópeZ-Roldán, Pedro (2017). «El efecto de la inmigración en la movilidad social intergeneracional en España». Revista Española de Sociología, 26 (3), 309-328. $<$ https://doi.org/10.22325/fes/res.2017.25>.

FERNÁNDEZ-HuERGA, Eduardo (2010). «La teoría de la segmentación del mercado de trabajo: enfoques, situación actual y perspectivas de futuro». Investigación Económica, 69 (273), 115-150.

- (2012). La teoría de la segmentación del mercado de trabajo. Una reconsideración desde la perspectiva institucionalista y poskeynesiana. Tesis doctoral de la Universidad de León.

FINA, Lluís y TOHARIA, Luis (1987). Las causas del paro en España: Un punto de vista estructural. Madrid: Fundación Instituto de Estudios Sociales Avanzados.

GarcíA-Nogueroles, Juan Miguel (2009). «Segmentación, precariedad y nueva ciudadanía. Consecuencias de los cambios en el modelo de empleo». Aposta. Revista de Ciencias Sociales, 41, 1-31.

García-Serrano, Carlos y Malo, Miguel A. (2013). Beyond the contract type segmentation in Spain. Country case study on labour market segmentation. Ginebra: International Labour Organization.

Gil-Hernández, Carlos; Marqués-Perales, Ildefonso y FaChelli, Sandra (2017). "Intergenerational social mobility in Spain between 1956 and 2011: The role of educational expansion and economic modernization in a late industrialized country». Research in Social Stratification and Mobility, 51, 14-27. <https://doi.org/10.1016/j.rssm.2017.06.002>.

GOLDTHORPE, John H. (2014). "The role of education in intergenerational social mobility: Problems from empirical research in sociology and some theoretical pointers from economics». Rationality and Society, 26 (3), 265-289. <https://doi.org/10.1177/1043463113519068>.

Gordon, David; EDWARDS, Richard y REICH, Michael (1986). Trabajo segmentado, trabajadores divididos. La transformación histórica del trabajo en los Estados Unidos. Madrid: Ministerio de Trabajo y Seguridad Social. <https://doi.org/10.5565/rev/papers/v32n0.1542>.

Grimshaw, Damian; Fagan, Colette; HeBSOn, Gail y Tavora, Isabel (eds.) (2017). Making work more equal: A new labour segmentation approach. Manchester: Manchester University Press. 
Huguet, Ana (1999). Segmentación en el mercado de trabajo español. Madrid: Consejo Económico Social.

Humphries, Jane y RubERY, Jill (1984). "The reconstitution of the supply side of the labour market: the relative autonomy of social reproduction». Cambridge Journal of Economics, 8, 331-346. <https://doi.org/10.1093/oxfordjournals.cje.a035554>.

ILO (International Labour Office) (1999). Trabajo decente. Memoria del Director General a la 87a reunión de la Conferencia Internacional del Trabajo. Ginebra. <http://www.ilo.org/public/spanish/standards/relm/ilc/ilc87/rep-i.htm>.

- (2016). Non-standard employment around the world: Understanding challenges, shaping prospects. Ginebra: ILO.

<http://www.ilo.org/global/publications/books/WCMS_534326/lang--en/index.htm>.

IsHIDA, Hiroshi y MIWA, Satoshi (eds.) (2011). "Comparative social mobility and late industrialization». Paper presented at Workshop of the Center for Research on Inequalities and the Life Course (CIQLE). Yale University (enero).

Kalleberg, Aarne; Wallace, Michael y Althauser, Robert (1981). «Economic segmentation, worker power and income inequality». American Journal of Sociology, 87 (3), 651-683. $<$ https://doi.org/10.1086/227499>.

KUCEL, Aleksander (2011). "Literature survey of the incidence of over-education: A sociological approach». Revista Española de Investigaciones Sociológicas, 134, 125-142.

LEONTARIDI, Marianthi R. (1998). «Segmented labour markets: Theory and evidence». Journal of Economic Surveys, 12 (1), 63-101. <https://doi.org/10.1111/1467-6419.00048>.

LÓPEZ-ROLDÁN, Pedro (1996). «La construcción de una tipología de segmentación del mercado de trabajo». Papers. Revista de Sociologia, 48, 41-58. $<$ https://doi.org/10.5565/rev/papers.1812>.

LópeZ-Roldán, Pedro y FACHelli, Sandra (2015). «Metodología de la investigación social cuantitativa». Bellaterra (Cerdanyola del Vallès): Dipòsit Digital de Documents, Universitat Autònoma de Barcelona. Edición digital. <http://ddd.uab.cat/record/129382>.

- (2017a). «Desigualdad y segmentación en los mercados de trabajo de España y Argentina». Anuario IET de Trabajo y Relaciones Laborales, 4, 15-33. <https://doi.org/10.5565/rev/aiet.51>.

- (2017b). «Social inequalities in Europe and Latin America. An analysis model based on life, occupational and educational trajectories research». INCASI Working Papers Series, 1. $<$ https://ddd.uab.cat/record/181855>.

López-Roldán, Pedro; Miguélez, Faustino; Lope, Andreu y Coller, Xavier (1998). "La segmentación laboral: hacia una tipología del ámbito productivo». Papers. Revista de Sociologia, 55, 45-77. <https://doi.org/10.5565/rev/papers.1932>.

MARQués-Perales, Ildefonso y Gil-Hernández, Carlos (2015). «Origen social y sobreeducación en los universitarios españoles: ¿es meritocrático el acceso a la clase de servicio?» Revista Española de Investigaciones Sociológicas, 150, 89-112. <https://doi.org/10.5477/cis/reis.150.89>.

MarsDEN, David (1999). A theory of employment systems: Micro-foundations of societal diversity. Oxford: Oxford University Press. <https://doi.org/10.1016/s0038-0296(02)01309-2>. 
Martín Artiles, Antonio (2008). «¿Modelo social de bajo coste?». Arxius de Sociologia, 18, 9-24.

Martín Artiles, Antonio; Lope, Andreu; Barrientos, Daniel y Moles, Benjamí (2017). «Adecuación y demanda de formación en la empresa. La inencontrable adecuación entre formación y empleo». Anuario IET de Trabajo y Relaciones Laborales, 4, 113-134.

<https://doi.org/10.5565/rev/aiet.58>.

MartíneZ-García, José Saturnino (2017). «Sobrecualificación de los titulados universitarios y movilidad social». Papers. Revista de Sociologia, 102 (1), 29-52. $<$ https://doi.org/10.5565/rev/papers.2225>.

Mata Greenwood, Adriana (1999). "OIT. Definiciones internacionales y futuro de las estadísticas del subempleo». Seminario sobre subempleo. Bogotá, Colombia, del 8 al 12 de noviembre.

<http://www.ilo.org/wcmsp5/groups/public/---dgreports/---stat/documents/publication/wcms_091441.pdf>.

Maurizio, Roxana (2016). Non-standard forms of employment in Latin America: Prevalence, characteristics and impacts on wages. Ginebra: International Labour Office. <http://www.ilo.org/wcmsp5/groups/public/---ed_protect/---protrav/---travail/ documents/publication/wcms_486160.pdf>.

MCGuinness, Seamus y WoOden, Mark (2007). «Overskilling, job insecurity and career mobility». IZA Discussion Papers, 2938. $<$ https://ssrn.com/abstract $=1004502>$.

MiCHON, François (2007). "What became of labour market segmentation in France: Its changing design». Économies et Sociétés, 28, 999-1026.

MiguéLEZ, Fausto (2004). «La flexibilidad laboral». Trabajo, 13, 17-36.

Miguélez, Fausto y LóPeZ-Roldán, Pedro (coord.) (2014). Crisis, empleo e inmigración en España. Un análisis de las trayectorias laborales. Bellaterra (Barcelona): Universitat Autònoma de Barcelona.

Miguélez, Fausto; Martín, Antonio; De Alós-Moner, Ramon; Esteban, Fernando; López-Roldán, Pedro; Molina, Oscar y Moreno, Sara (2011). Trayectorias laborales de los inmigrantes en España. Barcelona: Obra Social "la Caixa".

Miguélez, Fausto y Torns, Teresa (1998). «Introducción al análisis del trabajo y de la vida cotidiana». Papers. Revista de Sociologia, 55, 9-25. $<$ https://doi.org/10.5565/rev/papers.1930>.

Molina, Óscar y López-Roldán, Pedro (2015). «Occupational growth and nonstandard employment in the Spanish service sector: from upgrading to polarization». En: EICHHORST, Werner y MARX, Paul (eds.). Non-standard employment in a comparative perspective, 110-149. Cheltenham: Edward Elgar. <https://doi.org/10.4337/9781781001721.00011>.

NEFFA, Julio César (2008). «Las teorías de la segmentación de los mercados de trabajo». En: Eymard-Duverney, F. y NeFFA, J. C. Teorías económicas sobre el mercado de trabajo. III. Análisis institucionalistas, 95-139. Buenos Aires: Fondo de Cultura Económica y CEIL-PIETTE.

OCDE (2015). «In it together: Why less inequality benefits all». París: OCDE Publishing. <http://dx.doi.org/10.1787/9789264235120-en>.

ORTIZ, Luis (2010). «No the rigth job, but a secure one: over-education and temporary employment in France, Italy and Spain». Work, Employment and Society, 24 (1), 47-64. <https://doi.org/10.1177/0950017009353657>. 
Osterman, Paul (1985). Los mercados internos de trabajo. Madrid: Ministerio de Trabajo y Seguridad Social.

PAZ, Jorge (2013). «Segmentación del mercado de trabajo en la Argentina». Revista Desarrollo y Sociedad, 72, 105-156. <https://doi.org/10.13043/dys.72.3>.

PIASNA, Agnieszka (2017). 'Bad jobs' recovery? European Job Quality Index 2005-2015. Bruselas: European Trade Union Institute. Working Paper, 2017.06. <https://www.etui.org/content/download/33149/307231/file/WP-2017.06-WEB.pdfs.

PINTO, Aníbal (1970). «Naturaleza e implicaciones de la heterogeneidad estructural de América Latina». El Trimestre Económico, 37 (1), 145.

Polavieja, Javier G. (2003). «Temporary contracts and labour market segmentation in Spain: An employment-rent approach». European Sociological Review, 19 (5), 501-517. $<$ https://doi.org/10.1093/esr/19.5.501>.

Poy, Santiago (2017). «Heterogeneidad de la estructura ocupacional y segmentación del mercado de trabajo. Gran Buenos Aires, 1974-2014». Trabajo y Sociedad, 29, 353-376.

PREALC-OIT (1978). Sector informal. Funcionamiento y politicas. Santiago de Chile: PREALC, OIT.

Prebisch, R. (1949). El desarrollo económico de la América Latina y algunos de sus principales problemas. Santiago de Chile: Naciones Unidas. <https://repositorio.cepal.org/bitstream/handle/11362/40010/prebisch_desarrollo_problemas.pdf;jsessionid=2DC7C50C7FD90518E4794CD2168C22B8?seq uence $=1>$.

RECIO, Andreu (1988). Capitalismo y formas de contratación laboral. Madrid: Ministerio de Trabajo y Seguridad Social.

- (1991). «La segmentación del mercado de trabajo en España». En: MiguéLEZ, F. y PRIETO, C. (eds.). Las relaciones laborales en España, 97-115. Madrid: Siglo XXI.

RUBERY, Jill (1978). "Structured labour markets, worker organisation and low pay». Cambridge Journal of Economics, 2 (1), 17-36.

<https://doi.org/10.1093/oxfordjournals.cje.a035375>.

- (2007). «Developing segmentation theory: A thirty year perspective». Économies et Sociétés, 28 (6), 941-964.

RUBERY, Jill y WILKINSON, Frank (eds.) (1994). Employer strategy and the labour market. Nueva York: Oxford University Press.

SalviA, Agustín (2012). La trampa neoliberal. Un estudio sobre los cambios en la heterogeneidad estructural y la distribución del ingreso en la Argentina: 1990-2003. Buenos Aires: Eudeba.

Salvia, Agustín y Vera, Julieta (2003). «Heterogeneidad estructural, segmentación laboral y distribución del ingreso en el gran Buenos Aires: 1992-2003». En: NEFFA, J. C.; GARZA, J. de la y Muñiz, L. (comp.), Trabajo, empleo, calificaciones profesionales, relaciones de trabajo e identidades laborales, 349-410). Buenos Aires: Consejo Latinoamericano de Ciencias Sociales.

- (2016). "Calidad del empleo en Argentina (2004-2011). Una crítica al enfoque de las credenciales educativas». Revista de Ciencias Sociales, DS-FCS, 29 (38), enerojunio 2016, 37-58.

<http://www.scielo.edu.uy/scielo.php?script=sci_arttext\&pid=S079755382016000100003>.

SÁnCHEZ-López, Celia (2008). Propuesta metodológica para el estudio de la segmentación de los mercados de trabajo locales. Huelva: Universidad de Huelva. <http://rabida.uhu.es/dspace/bitstream/handle/10272/2954/b15172739. pdf? sequence $=1>$. 
SENGENBERgER, Werner (comp.) (1988). Lecturas sobre el mercado de trabajo en la República Federal de Alemania. Madrid: Ministerio de Trabajo y Seguridad Social. SPENCE, Michael (1973). «Job market signaling». The Quarterly Journal of Economics, 87 (3), 355-374.

VERA, Julieta (2013). «Informalidad y segmentación laboral desde la perspectiva estructuralista: una aplicación para la Argentina (1992-2010)». Labvoratorio, 25, 11-35. $<$ http://publicaciones.sociales.uba.ar/index.php/lavboratorio/article/download/117/104>.

Villa, Paola (1990). La estructuración de los mercados de trabajo. La siderurgia y la construcción en Italia. Madrid: Ministerio de Trabajo y Seguridad Social.

WILKINSON, Frank (ed.) (1981). The dynamics of labour market segmentation. Londres: Academic Press.

\section{Anexo}

Tabla 1. Distribución de frecuencias de las variables de segmentación del empleo. Población asalariada ocupada en 2016 de España y Argentina

\begin{tabular}{|c|c|c|c|c|c|c|}
\hline \multicolumn{7}{|c|}{ Caracterización de la demanda de empleo } \\
\hline \multicolumn{7}{|c|}{ Tipo de contrato y duración } \\
\hline \multirow[b]{2}{*}{ Dimensión } & \multicolumn{3}{|c|}{ España } & \multicolumn{3}{|c|}{ Argentina } \\
\hline & Variables & Frecuencia & $\%$ & Variables & Frecuencia & $\%$ \\
\hline \multirow[t]{19}{*}{ 1. Seguridad } & Indefinido & 22.472 & 75,6 & Indefinido & 10.885 & 61,2 \\
\hline & Al menos 1 mes & 2.957 & 9,9 & - & & \\
\hline & Temporal $<6$ meses & 2.580 & 8,7 & Temporal $<6$ meses & 1.788 & 10,1 \\
\hline & Temporal $>6$ meses & 1.714 & 5,8 & Temporal $>6$ meses & 888 & 5,0 \\
\hline & - & & & Trabajo informal & 4.226 & 23,8 \\
\hline & Sin datos ${ }^{1}$ & (314) & - & Sin datos ${ }^{1}$ & (9) & - \\
\hline & \multicolumn{6}{|c|}{ Tiempo en la empresa } \\
\hline & \multicolumn{3}{|c|}{ España } & \multicolumn{3}{|c|}{ Argentina } \\
\hline & Hasta 1 año & 5.260 & 17,5 & $<3$ meses & 1.394 & 7,9 \\
\hline & 2-3 años & 3.773 & 12,6 & 3-6 meses & 782 & 4,4 \\
\hline & 4-10 años & 7.080 & 23,6 & 6-12 meses & 890 & 5,1 \\
\hline & $11-20$ años & 7.171 & 23,9 & 1-5 años & 6.013 & 34,1 \\
\hline & Más de 20 años & 6.753 & 22,5 & $>5$ años & 8.542 & 48,5 \\
\hline & & & & Sin datos ${ }^{1}$ & $(176)$ & - \\
\hline & \multicolumn{6}{|c|}{ Tipo de jornada } \\
\hline & \multicolumn{3}{|c|}{ España } & \multicolumn{3}{|c|}{ Argentina } \\
\hline & Completa & 25.082 & 83,5 & Completa & 13.378 & 77,8 \\
\hline & Parcial & 4.955 & 16,5 & Parcial & 3.817 & 22,2 \\
\hline & & & & Sin datos & (603) & - \\
\hline
\end{tabular}


Tabla 1. Distribución de frecuencias de las variables de segmentación del empleo. Población asalariada ocupada en 2016 de España y Argentina (continuación)

\begin{tabular}{|c|c|c|c|c|c|c|}
\hline \multicolumn{7}{|c|}{ Caracterización de la demanda de empleo } \\
\hline \multirow[b]{3}{*}{ Dimensión } & \multicolumn{6}{|c|}{ Nivel ocupacionakl } \\
\hline & \multicolumn{3}{|c|}{ España } & \multicolumn{3}{|c|}{ Argentina } \\
\hline & Variables & Frecuencia & $\%$ & Variables & Frecuencia & $\%$ \\
\hline \multirow[t]{15}{*}{ 2. Cualificación } & $\begin{array}{l}\text { Directivos/as } \\
\text { y profesionales }\end{array}$ & 6.282 & 21,0 & Calificación profesional & 1.506 & 8,5 \\
\hline & $\begin{array}{l}\text { Técnicos/as } \\
\text { y administrativos/as }\end{array}$ & 6.998 & 23,4 & Calificación técnica & 3.089 & 17,4 \\
\hline & $\begin{array}{l}\text { Trabajador/a } \\
\text { cualificado/a }\end{array}$ & 12.343 & 41,4 & Calificación operativa & 8.358 & 47,0 \\
\hline & $\begin{array}{c}\text { Trabajador/a no } \\
\text { cualificado/a }\end{array}$ & 4.226 & 14,2 & No calificados/as & 4.845 & 27,2 \\
\hline & $\underline{\text { Sin datos }^{1}}$ & $(188)$ & - & Sin datos ${ }^{1}$ & $(134)$ & - \\
\hline & \multicolumn{6}{|c|}{ Nivel de supervisión } \\
\hline & \multicolumn{3}{|c|}{ España } & \multicolumn{3}{|c|}{ Argentina } \\
\hline & Variables & Frecuencia & $\%$ & Variables & Frecuencia & $\%$ \\
\hline & Empleado/a & 25.121 & 84,5 & Trabajadores/as & 16.865 & 95,3 \\
\hline & Encargado/a & 1.912 & 6,4 & - & & \\
\hline & Mando intermedio & 2.113 & 7,1 & Jefes/as & 536 & 3,0 \\
\hline & Director/a & 584 & 2,0 & Dirección & 296 & 1,7 \\
\hline & Sin datos ${ }^{1}$ & $(307)$ & - & Sin datos ${ }^{1}$ & $(53)$ & - \\
\hline & \multicolumn{6}{|c|}{ Decil de ingresos } \\
\hline & \multicolumn{3}{|c|}{ España } & \multicolumn{3}{|c|}{ Argentina } \\
\hline \multirow{12}{*}{$\begin{array}{l}\text { 3. Ingresos } \\
\text { salariales }\end{array}$} & Variables & Frecuencia & $\%$ & Variables & Frecuencia & $\%$ \\
\hline & Decil 1 & 2.949 & 9,8 & Decil 1 & 1.632 & 9,2 \\
\hline & Decil 2 & 2.832 & 9,4 & Decil 2 & 1.285 & 7,2 \\
\hline & Decil 3 & 2.904 & 9,7 & Decil 3 & 1.371 & 7,7 \\
\hline & Decil 4 & 3.017 & 10,0 & Decil 4 & 1.585 & 8,9 \\
\hline & Decil 5 & 2.906 & 9,7 & Decil 5 & 1.984 & 11,1 \\
\hline & Decil 6 & 3.086 & 10,3 & Decil 6 & 1.454 & 8,2 \\
\hline & Decil 7 & 2.991 & 10,0 & Decil 7 & 471 & 2,6 \\
\hline & Decil 8 & 3.074 & 10,2 & Decil 8 & 1.735 & 9,7 \\
\hline & Decil 9 & 3.163 & 10,5 & Decil 9 & 1.299 & 7,3 \\
\hline & Decil 10 & 3.115 & 10,4 & Decil 10 & 1.316 & 7,4 \\
\hline & & & & Sin datos & 3.668 & 20,6 \\
\hline
\end{tabular}


Tabla 1. Distribución de frecuencias de las variables de segmentación del empleo. Población asalariada ocupada en 2016 de España y Argentina (continuación)

\begin{tabular}{|c|c|c|c|c|c|c|}
\hline \multirow[b]{4}{*}{ Dimensión } & \multicolumn{6}{|c|}{ Caracterización de la demanda de empleo } \\
\hline & \multicolumn{6}{|c|}{ Sector de actividad } \\
\hline & \multicolumn{3}{|c|}{ España } & \multicolumn{3}{|c|}{ Argentina } \\
\hline & Variables & Frecuencia & $\%$ & Variables & Frecuencia & $\%$ \\
\hline \multirow{26}{*}{$\begin{array}{l}\text { 4. Características } \\
\text { de la empresa }\end{array}$} & Primario & 809 & 2,7 & Primario & 185 & 1,1 \\
\hline & Industria 1 & 1.494 & 5,0 & Industria 1 & 1.088 & 6,2 \\
\hline & Industria 2 & 1.895 & 6,3 & Industria 2 & 393 & 2,2 \\
\hline & Industria 3 & 1.380 & 4,6 & Industria 3 & 806 & 4,6 \\
\hline & Construcción & 1.454 & 4,8 & Construcción & 1.170 & 6,7 \\
\hline & Comercio & 6.302 & 21,0 & Comercio & 2.274 & 13,0 \\
\hline & $\begin{array}{l}\text { Transporte- } \\
\text { comunicaciones }\end{array}$ & 2.129 & 7,1 & $\begin{array}{l}\text { Transporte- } \\
\text { comunicaciones }\end{array}$ & 1.387 & 7,9 \\
\hline & $\begin{array}{l}\text { Financiero- } \\
\text { profesionales }\end{array}$ & 3.536 & 11,8 & $\begin{array}{l}\text { Financiero- } \\
\text { profesionales }\end{array}$ & 1.003 & 5,7 \\
\hline & Administración & 8.872 & 29,5 & Administración & 6.163 & 35,2 \\
\hline & Otros servicios & 2.166 & 7,2 & Otros servicios & 3.040 & 17,4 \\
\hline & & & & Sin datos & (245) & - \\
\hline & \multicolumn{6}{|c|}{ Titularidad de la empresa } \\
\hline & \multicolumn{3}{|c|}{ España } & \multicolumn{3}{|c|}{ Argentina } \\
\hline & Variables & Frecuencia & $\%$ & Variables & Frecuencia & $\%$ \\
\hline & Pública & 7.199 & 24,0 & Pública & 4.348 & 24,4 \\
\hline & Privada & 22.838 & 76,0 & Privada & 13.450 & 75,6 \\
\hline & & & & Sin datos ${ }^{1}$ & $(240)$ & - \\
\hline & \multicolumn{6}{|c|}{ Tamaño de la empresa } \\
\hline & \multicolumn{3}{|c|}{ España } & \multicolumn{3}{|c|}{ Argentina } \\
\hline & Variables & Frecuencia & $\%$ & Variables & Frecuencia & $\%$ \\
\hline & Hasta 5 & 5.270 & 17,5 & Hasta 5 & 4.767 & 26,8 \\
\hline & $6-10$ & 2.132 & 7,1 & $6-10$ & 1.679 & 9,4 \\
\hline & $11-49$ & 6.757 & 22,5 & $11-40$ & 2.684 & 15,1 \\
\hline & $50-250$ & 5.014 & 16,7 & $41-200$ & 2.255 & 12,7 \\
\hline & 250 y más & 4.428 & 14,7 & 200 y más & 2.632 & 14,8 \\
\hline & Sin datos & 6.436 & 21,4 & Sin datos & 3.782 & 21,3 \\
\hline
\end{tabular}


Tabla 1. Distribución de frecuencias de las variables de segmentación del empleo. Población asalariada ocupada en 2016 de España y Argentina (continuación)

\begin{tabular}{|c|c|c|c|c|c|c|}
\hline \multicolumn{7}{|c|}{ Caracterización de la oferta de empleo } \\
\hline \multirow[b]{3}{*}{ Dimensión } & \multicolumn{6}{|c|}{ Sexo } \\
\hline & \multicolumn{3}{|c|}{ España } & \multicolumn{3}{|c|}{ Argentina } \\
\hline & Variables & Frecuencia & $\%$ & Variables & Frecuencia & $\%$ \\
\hline \multirow[t]{4}{*}{ 5. Género } & Varón & 15.383 & 51,2 & Varón & 9.707 & 54,5 \\
\hline & Mujer & 14.654 & 48,8 & Mujer & 8.091 & 45,5 \\
\hline & \multicolumn{6}{|c|}{ Edad } \\
\hline & \multicolumn{3}{|c|}{ España } & \multicolumn{3}{|c|}{ Argentina } \\
\hline Dimensión & Variables & Frecuencia & $\%$ & Variables & Frecuencia & $\%$ \\
\hline \multirow[t]{11}{*}{ 6. Edad } & 16 a 24 años & 1.456 & 4,8 & 16 a 24 años & 2.380 & 13,4 \\
\hline & 25 a 29 años & 2.388 & 8,0 & 25 a 29 años & 2.404 & 13,5 \\
\hline & 30 a 34 años & 2.959 & 9,9 & 30 a 34 años & 2.285 & 12,8 \\
\hline & 35 a 39 años & 4.251 & 14,2 & 35 a 39 años & 2.497 & 14,0 \\
\hline & 40 a 44 años & 4.662 & 15,5 & 40 a 44 años & 2.202 & 12,4 \\
\hline & 45 a 49 años & 4.491 & 15,0 & 45 a 49 años & 1.813 & 10,2 \\
\hline & 50 a 54 años & 4.385 & 14,6 & 50 a 54 años & 1.624 & 9,1 \\
\hline & 55 a 59 años & 3.569 & 11,9 & 55 a 59 años & 1.241 & 7,0 \\
\hline & 60 y más años & 1.876 & 6,2 & 60 y más años & 1.351 & 7,6 \\
\hline & \multicolumn{6}{|c|}{ Nacionalidad } \\
\hline & \multicolumn{3}{|c|}{ España } & \multicolumn{3}{|c|}{ Argentina } \\
\hline Dimensión & Variables & Frecuencia & $\%$ & Variables & Frecuencia & $\%$ \\
\hline \multirow[t]{6}{*}{ 7. Inmigración } & Española & 27.700 & 92,2 & En esta u otra localidad & 14.482 & 81,4 \\
\hline & Doble nacionalidad & 709 & 2,4 & En otra provincia & 2.400 & 13,5 \\
\hline & Extranjera & 1.628 & 5,4 & En el extranjero & 909 & 5,1 \\
\hline & & & & Sin datos ${ }^{1}$ & (6) & - \\
\hline & \multicolumn{6}{|c|}{ Nivel educativo } \\
\hline & \multicolumn{3}{|c|}{ España } & \multicolumn{3}{|c|}{ Argentina } \\
\hline Dimensión & Variables & Frecuencia & $\%$ & Variables & Frecuencia & $\%$ \\
\hline \multirow[t]{5}{*}{ 8. Educación } & Primaria & 1.448 & 4,8 & Primaria completa & 5.942 & 33,5 \\
\hline & Secundaria $1^{\mathrm{a}}$ etapa & 8.124 & 27,0 & Secundaria & 5.894 & 33,2 \\
\hline & Secundaria $2^{\mathrm{a}}$ etapa & 7.027 & 23,4 & Terciario & 3.510 & 19,8 \\
\hline & Formación profesional & 4.187 & 13,9 & Universitario & 2.394 & 13,5 \\
\hline & Universitario & 9.251 & 30,8 & Sin datos ${ }^{1}$ & $(59)$ & - \\
\hline Total & & 30.037 & 100 & & 17.798 & 100 \\
\hline
\end{tabular}

(1) Categorías tratadas como ilustrativas con asignación aleatoria por baja frecuencia ( $1,9 \% 0$ menos). Tras la limpieza, de las 74 categorías se consideran 66 activas. (2) La agrupación de sectores se puede consultar en la información metodológica de la EPA. En particular, Industria 1 es: alimentación, textil, cuero, madera y papel; Industria 2: extractivas, refino de petróleo, industria química, farmacéutica, industria del caucho y materias plásticas, e Industria 3 . construcción de maquinaria, equipo eléctrico y material de transporte. Instalación y reparación industrial.

Fuente: INE. Encuesta de Población Activa, datos anuales de 2016.
(1) Categorías tratadas como ilustrativas con asignación aleatoria por baja frecuencia ( $1 \% 0$ menos). Tras la limpieza, de las 74 categorías se consideran 65 activas. (2) La agrupación se realizó en base al CAES 1.0. Se homogeneizó con la clasificación de España y los rubros diferentes se marcan a continuación: Industria 1: idem España. Industria 2: idem España + vidrio. Industria 3: idem España + fabr. de metales. Fabr. gas, electricidad y vapor. Administración: Adm. pública y servicios de apoyo. Otros servicios: agua, alcantarillado y gestión de desechos; alojamiento y servicios de comidas; Empleadores personal doméstico. (3) Monto por sueldos/jornales, salario familiar, horas extras, otras bonificaciones y tickets.

Fuente: INDEC. Encuesta Permanente de Hogares, $2^{\circ}$ trimestre de 2016. 
Tabla 2. Categorías características asociadas a los factores. España

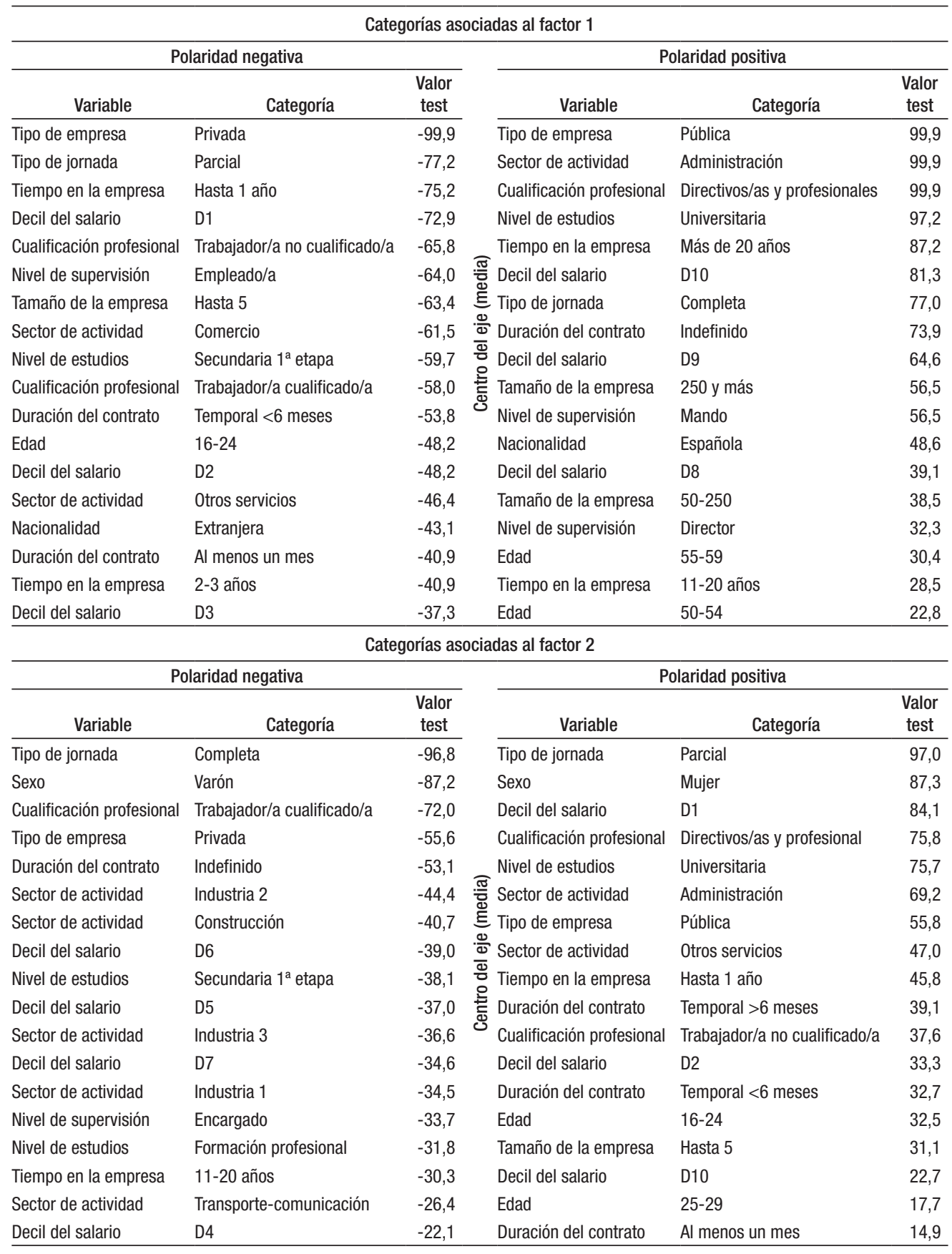

* Categorías características ordenadas según los valores test negativos y positivos en comparación a la media. Todos los valores de los test son significativos con probabilidad inferior al 0,05.

Fuente: elaboración propia a partir de la EPA de 2016 de España. 
Tabla 3. Categorías características asociadas a los factores. Argentina

Categorías asociadas al factor 1

\begin{tabular}{|c|c|c|c|c|c|}
\hline \multicolumn{3}{|c|}{ Polaridad negativa } & \multicolumn{3}{|c|}{ Polaridad positiva } \\
\hline Variable & Categoría & $\begin{array}{c}\text { Valor } \\
\text { test }\end{array}$ & Variable & Categoría & $\begin{array}{c}\text { Valor } \\
\text { test }\end{array}$ \\
\hline Tamaño de la empresa & Hasta 5 & $-94,5$ & Duración del contrato & Indefinido & 99,9 \\
\hline Cualificación profesional & No calificados & $-91,6$ & Tipo de empresa & Pública & 67,0 \\
\hline Sector de actividad & Otros servicios & $-79,2$ & Sector de actividad & Administración-servicios & 66,3 \\
\hline Duración del contrato & Temporal $<6$ meses & $-72,2$ & Tiempo en la empresa & $>5$ años & 63,2 \\
\hline Tipo de empresa & Privada & $-65,3$ & Tipo de jornada & Completa & 51,3 \\
\hline Nivel de estudios & Primaria completa & $-58,3$ & 這 Nivel de estudios & Universitario & 51,1 \\
\hline Duración del contrato & Informal & $-57,1$ & క్ Tamaño de la empresa & 200 y más & 50,3 \\
\hline Decil del salario & D1 & $-56,8$ & $\frac{\widetilde{\Phi}}{\Phi}$ Cualificación profesional & Calificación técnica & 45,0 \\
\hline Tipo de jornada & Parcial & $-56,2$ & 을 Cualificación profesional & Calificación profesional & 42,6 \\
\hline Tiempo en la empresa & $<3$ meses & $-48,0$ & 产 Decil del salario & D10 & 41,6 \\
\hline Decil del salario & $\mathrm{D} 2$ & $-46,0$ & Tamaño de la empresa & $41-200$ & 35,5 \\
\hline Edad & $16-24$ & $-40,0$ & Nivel de estudios & Terciario & 31,9 \\
\hline Nivel de supervisión & Trabajadores/as & $-30,6$ & Decil del salario & D9 & 31,7 \\
\hline Decil del salario & D3 & $-30,2$ & Decil del salario & D8 & 28,3 \\
\hline Sector de actividad & Construcción & $-23,7$ & Cualificación profesional & Calificación operativa & 23,6 \\
\hline Tiempo en la empresa & 1-5 años & $-22,7$ & Nivel de supervisión & Dirección & 23,4 \\
\hline Sexo & Mujer & $-22,4$ & Sexo & Varón & 22,5 \\
\hline Tiempo en la empresa & 3-6 meses & $-21,4$ & Nivel de supervisión & Jefes/as & 22,4 \\
\hline
\end{tabular}

Categorías asociadas al factor 2

\begin{tabular}{|c|c|c|c|c|c|c|}
\hline \multicolumn{3}{|c|}{ Polaridad negativa } & & \multicolumn{3}{|c|}{ Polaridad positiva } \\
\hline Variable & Categoría & $\begin{array}{c}\text { Valor } \\
\text { test }\end{array}$ & & Variable & Categoría & $\begin{array}{c}\text { Valor } \\
\text { test }\end{array}$ \\
\hline Sexo & Mujer & $-83,2$ & & Sexo & Varón & 82,9 \\
\hline Tipo de jornada & Parcial & $-64,6$ & & Cualificación profesional & Calificación operativa & 77,4 \\
\hline Sector de actividad & Administración-servicios & $-56,9$ & $\frac{\pi}{0}$ & Tipo de jornada & Completa & 63,0 \\
\hline Tipo de empresa & Pública & $-54,6$ & $\stackrel{\oplus}{\underline{E}}$ & Tipo de empresa & Privada & 54,8 \\
\hline Duración del contrato & Temporal $<6$ meses & $-48,6$ & $\frac{0}{\Phi}$ & Sector de actividad & Construcción & 38,3 \\
\hline Sector de actividad & Otros servicios & $-48,3$ & $\bar{\Phi}$ & Sector de actividad & Comercio & 33,9 \\
\hline Nivel de estudios & Universitario & $-47,7$ & 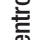 & Sector de actividad & Transporte-comunicación & 31,9 \\
\hline Cualificación profesional & Calificación profesional & $-41,2$ & త్తి & Tamaño de la empresa & 43261 & 30,5 \\
\hline Cualificación profesional & Calificación técnica & $-38,0$ & "̄ & Sector de actividad & Industria 1 & 30,2 \\
\hline Cualificación profesional & No calificados & $-29,6$ & $\stackrel{\text { है }}{.0}$ & Nivel de estudios & Secundaria & 30,0 \\
\hline Decil del salario & $\mathrm{D} 2$ & $-29,1$ & $\frac{\Phi}{\Phi}$ & Edad & $16-24$ & 29,0 \\
\hline Decil del salario & D1 & $-24,4$ & 잉 & Sector de actividad & Industria 3 & 27,4 \\
\hline Nivel de supervisión & Dirección & $-24,1$ & 壳 & Nivel de estudios & Primaria completa & 25,0 \\
\hline Nivel de estudios & Terciario & $-23,8$ & & Duración del contrato & Informal & 24,5 \\
\hline Tamaño de la empresa & Hasta 5 & $-19,5$ & & Tamaño de la empresa & Sin datos & 23,7 \\
\hline Decil del salario & D10 & $-19,3$ & & Edad & $25-29$ & 19,3 \\
\hline Tamaño de la empresa & 200 y más & $-17,7$ & & Decil del salario & D5 & 15,5 \\
\hline Edad & $55-59$ & $-16,2$ & & Sector de actividad & Industria 2 & 15,2 \\
\hline
\end{tabular}

* Categorías características ordenadas según los valores test negativos y positivos en comparación a la media. Todos los valores de los test son significativos con probabilidad inferior al 0,05.

Fuente: elaboración propia a partir de la EPH de 2016 de Argentina. 
Tabla 4. Caracterización de la tipología de segmentación en 4 grupos según las categorías de las variables originales. España

\begin{tabular}{|c|c|c|c|c|}
\hline \multicolumn{5}{|c|}{ Tipo 1: Segmento secundario inferior (4.391 casos, $14,6 \%$ ) } \\
\hline Variable & Categorías características & $\begin{array}{c}\text { \% de la } \\
\text { categoría } \\
\text { en el tipo }\end{array}$ & $\begin{array}{c}\% \text { de la } \\
\text { categoría } \\
\text { sobre el total }\end{array}$ & $\begin{array}{c}\text { Valor } \\
\text { test }\end{array}$ \\
\hline Tipo de jornada & Parcial & 79,8 & 16,5 & 106,3 \\
\hline Decil del salario & D1 & 59,4 & 9,8 & 98,7 \\
\hline Tiempo en la empresa & Hasta 1 año & 50,4 & 17,5 & 55,5 \\
\hline Cualificación profesional & Trabajador/a no cualificado/a & 41,3 & 14,1 & 49,5 \\
\hline Sector de actividad & Otros servicios & 27,7 & 7,2 & 47,6 \\
\hline Tamaño de la empresa & Hasta 5 & 44,6 & 17,5 & 46,1 \\
\hline Sexo & Mujer & 78,1 & 48,8 & 43,0 \\
\hline Edad & $16-24$ & 18,9 & 4,8 & 39,0 \\
\hline Duración del contrato & Temporal $<6$ meses & 25,8 & 8,6 & 38,2 \\
\hline Decil del salario & D2 & 26,6 & 9,4 & 36,8 \\
\hline Tipo de empresa & Privada & 93,3 & 76,0 & 32,2 \\
\hline Nivel de supervisión & Empleado/a & 97,3 & 83,6 & 30,9 \\
\hline Duración del contrato & Temporal $>6$ meses & 13,6 & 5,7 & 21,7 \\
\hline Duración del contrato & Al menos un mes & 19,0 & 9,8 & 20,3 \\
\hline Nacionalidad & Extranjera & 12,3 & 5,4 & 19,5 \\
\hline Edad & $25-29$ & 15,4 & 8,0 & 18,0 \\
\hline Nivel de estudios & Primaria & 10,8 & 4,8 & 17,8 \\
\hline Sector de actividad & Comercio & 29,1 & 21,0 & 13,8 \\
\hline Tamaño de la empresa & Sin datos & 29,4 & 21,4 & 13,4 \\
\hline Tiempo en la empresa & 2-3 años & 18,9 & 12,6 & 13,1 \\
\hline Nacionalidad & Española y doble & 4,9 & 2,4 & 10,6 \\
\hline Nivel de estudios & Secundaria $1^{\mathrm{a}}$ etapa & 33,6 & 27,0 & 10,4 \\
\hline Sector de actividad & Primario & 5,0 & 2,7 & 9,3 \\
\hline Sector de actividad & Financiero-profesional & 15,7 & 11,8 & 8,4 \\
\hline Nivel de estudios & Secundaria $2^{\mathrm{a}}$ etapa & 25,0 & 23,4 & 2,6 \\
\hline
\end{tabular}

Tipo 2: Segmento secundario superior (7.256 casos, $24,2 \%)$

\begin{tabular}{llccc}
\hline Variable & Categorías características & $\begin{array}{c}\text { \% de la } \\
\text { categoría } \\
\text { en el tipo }\end{array}$ & $\begin{array}{c}\text { \% de la } \\
\text { categoría } \\
\text { sobre el total }\end{array}$ & $\begin{array}{c}\text { Valor } \\
\text { test }\end{array}$ \\
\hline Tipo de empresa & Privada & 96,2 & 76,0 & 52,4 \\
Decil del salario & D3 & 25,4 & 9,7 & 47,8 \\
Sector de actividad & Comercio & 37,1 & 21,0 & 37,1 \\
Nivel de supervisión & Empleado/a & 95,7 & 83,6 & 35,5 \\
Decil del salario & D4 & 21,7 & 10,0 & 35,2 \\
Tiempo en la empresa & Hasta 1 año & 31,4 & 17,5 & 34,1 \\
Decil del salario & D2 & 20,2 & 9,4 & 33,5 \\
Cualificación profesional & Trabajador/a no cualificado/a & 24,3 & 14,1 & 27,4 \\
Cualificación profesional & Trabajador/a cualificado/a & 53,6 & 41,1 & 24,6 \\
Duración del contrato & Temporal <6 meses & 16,1 & 8,6 & 24,5 \\
Tamaño de la empresa & Hasta 5 & 27,4 & 17,5 & 24,4
\end{tabular}


Tabla 4. Caracterización de la tipología de segmentación en 4 grupos según las categorías de las variables originales. España (continuación)

\begin{tabular}{|c|c|c|c|c|}
\hline \multicolumn{5}{|c|}{ Tipo 2: Segmento secundario superior (7.256 casos, $24,2 \%)$} \\
\hline Variable & Categorías características & $\begin{array}{c}\% \text { de la } \\
\text { categoría } \\
\text { en el tipo }\end{array}$ & $\begin{array}{c}\% \text { de la } \\
\text { categoría } \\
\text { sobre el total }\end{array}$ & $\begin{array}{l}\text { Valor } \\
\text { test }\end{array}$ \\
\hline Tiempo en la empresa & $2-3$ años & 21,2 & 12,6 & 24,3 \\
\hline Nivel de estudios & Secundaria $1^{\mathrm{a}}$ etapa & 38,2 & 27,0 & 24,0 \\
\hline Duración del contrato & Al menos un mes & 17,4 & 9,8 & 23,3 \\
\hline Edad & $25-29$ & 14,1 & 8,0 & 21,0 \\
\hline Nacionalidad & Extranjera & 10,4 & 5,4 & 20,2 \\
\hline Nivel de estudios & Primaria & 9,0 & 4,8 & 17,7 \\
\hline Tamaño de la empresa & Sin datos & 29,1 & 21,4 & 17,7 \\
\hline Sector de actividad & Primario & 5,8 & 2,7 & 17,5 \\
\hline Edad & $16-24$ & 7,8 & 4,8 & 12,6 \\
\hline Decil del salario & D5 & 13,3 & 9,7 & 11,7 \\
\hline Nacionalidad & Española y doble & 4,2 & 2,4 & 10,9 \\
\hline Edad & $30-34$ & 13,2 & 9,9 & 10,6 \\
\hline Tiempo en la empresa & 4-10 años & 27,8 & 23,6 & 9,5 \\
\hline Sexo & Mujer & 53,3 & 48,8 & 8,9 \\
\hline Nivel de estudios & Secundaria $2^{\mathrm{a}}$ etapa & 27,2 & 23,4 & 8,7 \\
\hline Tamaño de la empresa & $6-10$ & 9,4 & 7,1 & 8,5 \\
\hline Sector de actividad & Construcción & 6,7 & 4,8 & 8,2 \\
\hline Duración del contrato & Temporal $>6$ meses & 7,3 & 5,7 & 6,4 \\
\hline Sector de actividad & Financiero-Profesional & 13,8 & 11,8 & 5,9 \\
\hline Sector de actividad & Otros servicios & 8,8 & 7,2 & 5,9 \\
\hline Tipo de jornada & Completa & 85,4 & 83,5 & 5,1 \\
\hline Edad & $35-39$ & 15,5 & 14,2 & 3,7 \\
\hline
\end{tabular}

Tipo 3: Segmento primario inferior (9.900 casos, $33,0 \%)$

\begin{tabular}{llccc}
\hline Variable & Categorías características & $\begin{array}{c}\text { \% de la } \\
\text { categoría } \\
\text { en el tipo }\end{array}$ & $\begin{array}{c}\text { \% de la } \\
\text { categoría } \\
\text { sobre el total }\end{array}$ & $\begin{array}{c}\text { Valor } \\
\text { test }\end{array}$ \\
\hline Tipo de jornada & Completa & 99,6 & 83,5 & 63,3 \\
Sexo & Varón & 74,9 & 51,2 & 58,7 \\
Duración del contrato & Indefinido & 92,1 & 74,8 & 52,1 \\
Tipo de empresa & Privada & 92,8 & 76,0 & 51,6 \\
Cualificación profesional & Trabajador/a cualificado/a & 59,3 & 41,1 & 44,9 \\
Sector de actividad & Industria 2 & 14,0 & 6,3 & 37,0 \\
Decil del salario & D6 & 19,3 & 10,3 & 34,7 \\
Decil del salario & D7 & 18,3 & 10,0 & 32,7 \\
Sector de actividad & Industria 3 & 10,2 & 4,6 & 31,1 \\
Tiempo en la empresa & $11-20$ años & 34,7 & 23,9 & 30,2 \\
Nivel de estudios & Formación profesional & 22,0 & 13,9 & 27,5 \\
Nivel de supervisión & Encargado & 12,1 & 6,4 & 27,3 \\
Decil del salario & D5 & 16,5 & 9,7 & 27,0 \\
Sector de actividad & Industria 1 & 9,9 & 5,0 & 26,3 \\
\hline Cualificación profesional & Técnicos/as y administrativos/as & 32,3 & 23,3 & 25,5 \\
Nivel de estudios & Secundaria 1a etapa & 35,9 & 27,0 & 24,0 \\
Sector de actividad & Transporte-comunicaciones & 12,1 & 7,1 & 22,8
\end{tabular}


Tabla 4. Caracterización de la tipología de segmentación en 4 grupos según las categorías de las variables originales. España (continuación)

\begin{tabular}{llccc}
\hline \multicolumn{5}{c}{ Tipo 3: Segmento primario inferior (9.900 casos, 33,0\%) } \\
\hline Variable & Categorías características & $\begin{array}{c}\text { \% de la } \\
\text { categoría } \\
\text { en el tipo }\end{array}$ & $\begin{array}{c}\text { \% de la } \\
\text { categoría } \\
\text { sobre el total }\end{array}$ & $\begin{array}{c}\text { Valor } \\
\text { test }\end{array}$ \\
\hline Sector de actividad & Construcción & 8,8 & 4,8 & 21,5 \\
Nacionalidad & Española & 96,0 & 92,2 & 18,1 \\
Tamaño de la empresa & $11-49$ & 27,2 & 22,5 & 13,6 \\
Decil del salario & D8 & 13,6 & 10,2 & 13,4 \\
Nivel de estudios & Secundaria 2a etapa & 27,9 & 23,4 & 12,9 \\
Tamaño de la empresa & $50-250$ & 20,1 & 16,7 & 11,1 \\
Edad & $40-44$ & 18,6 & 15,5 & 10,3 \\
Tiempo en la empresa & $4-10$ años & 26,6 & 23,6 & 8,7 \\
Edad & $45-49$ & 17,3 & 15,0 & 8,0 \\
Tamaño de la empresa & $6-10$ & 8,4 & 7,1 & 5,9 \\
Edad & $35-39$ & 15,8 & 14,2 & 5,6 \\
Edad & $50-54$ & 16,1 & 14,6 & 5,2 \\
Decil del salario & D4 & 11,1 & 10,0 & 4,3 \\
Tiempo en la empresa & Más de 20 años & 23,9 & 22,5 & 4,1 \\
Edad & 30-34 & 10,8 & 9,9 & 3,9 \\
Sector de actividad & Comercio & 21,9 & 21,0 & 2,6 \\
\hline
\end{tabular}

Tipo 4: Segmento primario superior ( 8.490 casos, $28,3 \%)$

\begin{tabular}{llccc}
\hline & Categorías características & $\begin{array}{c}\text { \% de la } \\
\text { categoría } \\
\text { en el tipo }\end{array}$ & $\begin{array}{c}\text { \% de la } \\
\text { categoría } \\
\text { sobre el total }\end{array}$ & $\begin{array}{c}\text { Valor } \\
\text { test }\end{array}$ \\
\hline Tipo de empresa & Pública & 69,7 & 24,0 & 113,8 \\
Sector de actividad & Administración & 75,7 & 29,5 & 108,7 \\
Cualificación profesional & Directivos/as y profesionales & 62,4 & 20,9 & 107,6 \\
Nivel de estudios & Universitaria & 74,6 & 30,8 & 101,9 \\
Decil del salario & D10 & 30,1 & 10,4 & 66,5 \\
Tiempo en la empresa & Más de 20 años & 46,5 & 22,5 & 60,3 \\
Decil del salario & D9 & 26,4 & 10,5 & 53,0 \\
Nivel de supervisión & Mando & 18,5 & 7,0 & 45,7 \\
Tamaño de la empresa & 250 y más & 28,7 & 14,7 & 40,9 \\
Tipo de jornada & Completa & 95,8 & 83,5 & 40,0 \\
Duración del contrato & Indefinido & 87,8 & 74,8 & 34,2 \\
Nacionalidad & Española & 98,5 & 92,2 & 29,0 \\
Decil del salario & D8 & 18,5 & 10,2 & 28,4 \\
Tamaño de la empresa & $50-250$ & 24,6 & 16,7 & 22,4 \\
Edad & $55-59$ & 17,9 & 11,9 & 19,6 \\
Sexo & Mujer & 57,4 & 48,8 & 18,8 \\
Edad & 60 y más & 10,2 & 6,2 & 16,8 \\
Edad & $50-54$ & 19,0 & 14,6 & 13,2 \\
Tiempo en la empresa & $11-20$ años & 27,5 & 23,9 & 9,0 \\
Tamaño de la empresa & $11-49$ & 25,1 & 22,5 & 6,8 \\
Edad & $45-49$ & 16,1 & 15,0 & 3,4 \\
\hline * Cadtgor & & & & \\
\hline
\end{tabular}

* Categorías características ordenadas según los valores test de la comparación de proporciones. Todos los valores de los test son significativos con probabilidad inferior al 0,05.

Fuente: elaboración propia a partir de la EPA de 2016. 
Tabla 5. Caracterización de la tipología de segmentación en 4 grupos según las categorías de las variables originales. Argentina

\begin{tabular}{|c|c|c|c|c|}
\hline \multicolumn{5}{|c|}{ Tipo 1: Segmento secundario inferior (2.471 casos, $13,9 \%)$} \\
\hline Variable & Categorías características & $\begin{array}{c}\% \text { de la } \\
\text { categoría en } \\
\text { el tipo }\end{array}$ & $\begin{array}{c}\text { \% de la } \\
\text { categoría sobre } \\
\text { el total }\end{array}$ & $\begin{array}{c}\text { Valor } \\
\text { test }\end{array}$ \\
\hline Sector de actividad & Otros servicios & 81,0 & 17,1 & 79,2 \\
\hline Cualificación profesional & No calificados & 93,4 & 26,9 & 77,1 \\
\hline Tamaño de la empresa & Hasta 5 & 89,6 & 26,8 & 72,2 \\
\hline Duración del contrato & Temporal $<6$ meses & 58,9 & 10,0 & 71,0 \\
\hline Tipo de jornada & Parcial & 70,7 & 21,4 & 58,1 \\
\hline Sexo & Mujer & 90,2 & 45,5 & 50,5 \\
\hline Decil del salario & D1 & 36,2 & 9,2 & 42,0 \\
\hline Decil del salario & $\mathrm{D} 2$ & 29,9 & 7,2 & 38,6 \\
\hline Nivel de estudios & Primaria completa & 60,4 & 33,4 & 29,7 \\
\hline Tipo de empresa & Privada & 95,7 & 74,9 & 29,6 \\
\hline Tiempo en la empresa & $<3$ meses & 22,1 & 7,8 & 24,7 \\
\hline Duración del contrato & Informal & 35,8 & 23,7 & 14,6 \\
\hline Nivel de supervisión & Trabajadores/as & 99,4 & 94,8 & 13,6 \\
\hline Lugar de nacimiento & En el Exterior & 11,0 & 5,1 & 12,8 \\
\hline Lugar de nacimiento & En otra provincia & 20,5 & 13,5 & 10,4 \\
\hline Tiempo en la empresa & $1-5$ años & 42,6 & 33,8 & 9,8 \\
\hline Tiempo en la empresa & 3-6 meses & 8,2 & 4,4 & 9,0 \\
\hline Decil del salario & D3 & 12,2 & 7,7 & 8,4 \\
\hline Edad & $50-54$ & 12,7 & 9,1 & 6,3 \\
\hline Edad & $55-59$ & 9,5 & 7,0 & 5,1 \\
\hline Edad & $16-24$ & 16,3 & 13,4 & 4,4 \\
\hline Edad & 60 y más & 9,8 & 7,6 & 4,2 \\
\hline
\end{tabular}

\begin{tabular}{|c|c|c|c|c|}
\hline Variable & Categorías características & $\begin{array}{c}\% \text { de la } \\
\text { categoría en } \\
\text { el tipo }\end{array}$ & $\begin{array}{c}\% \text { de la } \\
\text { categoría sobre } \\
\text { el total }\end{array}$ & $\begin{array}{c}\text { Valor } \\
\text { test }\end{array}$ \\
\hline Duración del contrato & Informal & 58,6 & 23,7 & 56,2 \\
\hline Tipo de empresa & Privada & 95,1 & 74,9 & 37,9 \\
\hline Edad & $16-24$ & 32,4 & 13,4 & 37,4 \\
\hline Tamaño de la empresa & Hasta 5 & 48,6 & 26,8 & 34,4 \\
\hline Sector de actividad & Construcción & 19,2 & 6,6 & 33,4 \\
\hline Nivel de estudios & Primaria completa & 52,1 & 33,4 & 28,1 \\
\hline Sector de actividad & Comercio & 26,6 & 12,8 & 28,1 \\
\hline Decil del salario & D3 & 18,8 & 7,7 & 27,5 \\
\hline Cualificación profesiona & INo calificados & 42,4 & 26,9 & 24,6 \\
\hline Tiempo en la empresa & $<3$ meses & 17,6 & 7,8 & 24,2 \\
\hline Sexo & Varón & 68,2 & 54,5 & 20,1 \\
\hline Duración del contrato & Temporal $>6$ meses & 11,4 & 5,0 & 19,4 \\
\hline Decil del salario & D4 & 16,6 & 8,9 & 18,2 \\
\hline Nivel de supervisión & Trabajadores/as & 99,3 & 94,8 & 17,3 \\
\hline
\end{tabular}


Tabla 5. Caracterización de la tipología de segmentación en 4 grupos según las categorías de las variables originales. Argentina (continuación)

\begin{tabular}{|c|c|c|c|c|}
\hline \multicolumn{5}{|c|}{ Tipo 2: Segmento secundario superior (4.061 casos, $22,8 \%$ ) } \\
\hline Variable & Categorías características & $\begin{array}{c}\% \text { de la } \\
\text { categoría en } \\
\text { el tipo }\end{array}$ & $\begin{array}{c}\% \text { de la } \\
\text { categoría sobre } \\
\text { el total }\end{array}$ & $\begin{array}{c}\text { Valor } \\
\text { test }\end{array}$ \\
\hline Tiempo en la empresa & $6-12$ meses & 10,4 & 5,0 & 16,5 \\
\hline Tiempo en la empresa & 3-6 meses & 8,9 & 4,4 & 14,6 \\
\hline Tiempo en la empresa & $1-5$ años & 40,8 & 33,8 & 10,6 \\
\hline Tamaño de la empresa & $6-10$ & 13,9 & 9,4 & 10,5 \\
\hline Decil del salario & D1 & 13,2 & 9,2 & 9,7 \\
\hline Edad & $25-29$ & 18,1 & 13,5 & 9,4 \\
\hline Cualificación profesional & Calificación operativa & 52,2 & 46,7 & 7,9 \\
\hline Sector de actividad & Industria 1 & 8,6 & 6,1 & 7,1 \\
\hline Decil del salario & D2 & 9,3 & 7,2 & 5,7 \\
\hline Lugar de nacimiento & En esta $u$ otra local & 84,2 & 81,4 & 5,3 \\
\hline Lugar de nacimiento & En el exterior & 6,5 & 5,1 & 4,3 \\
\hline Nivel de estudios & Secundaria & 35,6 & 33,1 & 3,8 \\
\hline Tipo de jornada & Completa & 77,4 & 75,2 & 3,8 \\
\hline \multicolumn{5}{|c|}{ Tipo 3: Segmento primario inferior $(5.820,32,7 \%)$} \\
\hline Variable & Categorías características & $\begin{array}{c}\% \text { de la } \\
\text { categoría en } \\
\text { el tipo }\end{array}$ & $\begin{array}{c}\text { \% de la } \\
\text { categoría sobre } \\
\text { el total }\end{array}$ & $\begin{array}{c}\text { Valor } \\
\text { test }\end{array}$ \\
\hline Cualificación profesional & Calificación operativa & 78,7 & 46,7 & 60,8 \\
\hline Duración del contrato & Indefinido & 87,1 & 61,2 & 52,1 \\
\hline Sexo & Varón & 80,4 & 54,5 & 49,8 \\
\hline Tipo de jornada & Completa & 94,6 & 75,2 & 46,0 \\
\hline Tipo de empresa & Privada & 89,8 & 74,9 & 33,8 \\
\hline Sector de actividad & Transporte-comunicaciones & 16,3 & 7,8 & 28,5 \\
\hline Nivel de estudios & Secundaria & 46,4 & 33,1 & 25,9 \\
\hline Sector de actividad & Industria 3 & 10,2 & 4,5 & 24,4 \\
\hline Tamaño de la empresa & Sin datos & 31,3 & 21,3 & 22,3 \\
\hline Sector de actividad & Industria 1 & 11,4 & 6,1 & 19,6 \\
\hline Decil del salario & D8 & 15,9 & 9,7 & 18,5 \\
\hline Tiempo en la empresa & $>5$ años & 57,5 & 48,0 & 17,8 \\
\hline Decil del salario & D6 & 13,2 & 8,2 & 16,4 \\
\hline Tamaño de la empresa & $6-10$ & 14,5 & 9,4 & 15,7 \\
\hline Sector de actividad & Industria 2 & 4,7 & 2,2 & 14,9 \\
\hline Decil del salario & D5 & 15,3 & 11,1 & 12,1 \\
\hline Decil del salario & D7 & 4,5 & 2,6 & 10,1 \\
\hline Decil del salario & D9 & 10,0 & 7,3 & 9,5 \\
\hline Sector de actividad & Comercio & 16,2 & 12,8 & 9,4 \\
\hline Edad & $25-29$ & 16,7 & 13,5 & 8,6 \\
\hline Tamaño de la empresa & $11-40$ & 18,2 & 15,1 & 7,9 \\
\hline Edad & $30-34$ & 15,6 & 12,8 & 7,5 \\
\hline Nivel de supervisión & Jefes/as & 4,4 & 3,0 & 7,2 \\
\hline
\end{tabular}


Tabla 5. Caracterización de la tipología de segmentación en 4 grupos según las categorías de las variables originales. Argentina (continuación)

\begin{tabular}{|c|c|c|c|c|}
\hline \multicolumn{5}{|c|}{ Tipo 3: Segmento primario inferior $(5.820,32,7 \%)$} \\
\hline Variable & Categorías características & $\begin{array}{c}\% \text { de la } \\
\text { categoría en } \\
\text { el tipo }\end{array}$ & $\begin{array}{c}\% \text { de la } \\
\text { categoría sobre } \\
\text { el total }\end{array}$ & $\begin{array}{c}\text { Valor } \\
\text { test }\end{array}$ \\
\hline Decil del salario & Sin datos & 23,6 & 20,6 & 6,9 \\
\hline Tamaño de la empresa & $41-200$ & 14,9 & 12,7 & 6,1 \\
\hline Lugar de nacimiento & En esta u otra local & 83,3 & 81,4 & 4,6 \\
\hline Sector de actividad & Financiero-profesional & 6,4 & 5,6 & 3,2 \\
\hline \multicolumn{5}{|c|}{ Tipo 4: Segmento primario superior (5.446 casos, $30,6 \%$ ) } \\
\hline Variable & Categorías características & $\begin{array}{c}\% \text { de la } \\
\text { categoría en } \\
\text { el tipo }\end{array}$ & $\begin{array}{c}\% \text { de la } \\
\text { categoría sobre } \\
\text { el total }\end{array}$ & $\begin{array}{c}\text { Valor } \\
\text { test }\end{array}$ \\
\hline Tipo de empresa & Pública & 63,9 & 23,6 & 82,8 \\
\hline Sector de actividad & Administración & 78,9 & 34,6 & 82,8 \\
\hline Nivel de estudios & Universitario & 38,0 & 13,5 & 61,7 \\
\hline Cualificación profesional & Calificación técnica & 41,6 & 17,3 & 54,8 \\
\hline Duración del contrato & Indefinido & 88,7 & 61,2 & 53,1 \\
\hline Cualificación profesional & Calificación profesional & 24,5 & 8,3 & 50,3 \\
\hline Tiempo en la empresa & $>5$ años & 70,4 & 48,0 & 40,1 \\
\hline Tamaño de la empresa & 200 y más & 31,1 & 14,8 & 39,0 \\
\hline Nivel de estudios & Terciario & 35,7 & 19,7 & 34,3 \\
\hline Decil del salario & D10 & 17,5 & 7,4 & 32,5 \\
\hline Sexo & Mujer & 63,0 & 45,5 & 31,3 \\
\hline Tamaño de la empresa & $41-200$ & 22,8 & 12,7 & 25,8 \\
\hline Decil del salario & D9 & 12,5 & 7,3 & 16,8 \\
\hline Tamaño de la empresa & $11-40$ & 20,7 & 15,1 & 13,5 \\
\hline Edad & $40-44$ & 16,4 & 12,4 & 10,4 \\
\hline Decil del salario & D8 & 13,1 & 9,7 & 9,7 \\
\hline Edad & $55-59$ & 9,7 & 7,0 & 9,4 \\
\hline Sector de actividad & Financiero-profesional & 8,1 & 5,6 & 9,4 \\
\hline Nivel de supervisión & Jefes/as & 4,8 & 3,0 & 8,9 \\
\hline Edad & $50-54$ & 11,8 & 9,1 & 8,0 \\
\hline Edad & $35-39$ & 17,0 & 14,0 & 7,5 \\
\hline Edad & $45-49$ & 12,8 & 10,2 & 7,4 \\
\hline Tipo de jornada & Sin datos & 4,6 & 3,4 & 5,6 \\
\hline Lugar de nacimiento & En esta u otra local & 83,1 & 81,4 & 3,9 \\
\hline Edad & 60 y más & 8,6 & 7,6 & 3,4 \\
\hline
\end{tabular}

* Categorías características ordenadas según los valores test de la comparación de proporciones. Todos los valores de los test son significativos con probabilidad inferior al 0,05.

Fuente: elaboración propia a partir de la EPH de 2016. 